\title{
Assessment of biomass potentials of microalgal communities in open pond raceways using mass cultivation
}

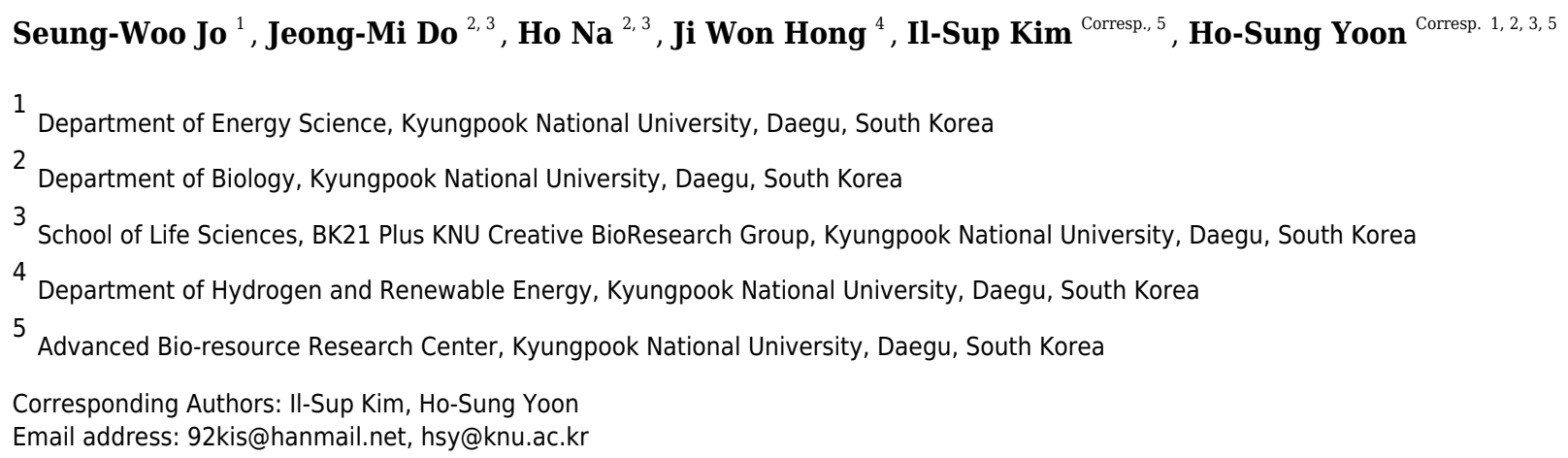

Metagenome studies have provided us with insight into the complex interactions of microorganisms with their environments and hosts. Few studies have focused on microalgae-associated metagenomes, and no study has addressed aquatic microalgae and their bacterial communities in open pond raceways (OPRs). This study explored the possibility of using microalgal biomasses from OPRs for biodiesel and biofertilizer production. The fatty acid profiles of the biomasses and the physical and chemical properties of derived fuels were evaluated. In addition, the phenotype-based environmental adaptation ability of soybean plants was assessed. The growth rate, biomass, and lipid productivity of microalgae were also examined during mass cultivation from April to November 2017. Metagenomics analysis using MiSeq identified 127 eukaryotic phylotypes following mass cultivation with (OPR 1) or without (OPR 3) a semitransparent film. Of these, $\sim 80$ phylotypes were found in both OPRs, while 23 and 24 phylotypes were identified in OPRs 1 and 3, respectively. The phylotypes belonged to various genera, such as Desmodesmus, Pseudopediastrum, Tetradesmus, and Chlorella, of which, the dominant microalgal species was Desmodesmus sp.. On average, OPRs 1 and 3 produced $\sim 8.6$ and $9.9 \mathrm{~g} \cdot \mathrm{m}^{-2} \cdot \mathrm{d}^{-1}\left(0.307\right.$ and $\left.0.309 \mathrm{DW} \cdot \mathrm{L}^{-1}\right)$ of total biomass, respectively, of which 14.0 and 13.3 wt\% respectively, was lipid content. Fatty acid profiling revealed that total saturated fatty acids (mainly $\mathrm{C} 16: 0$ ) of biodiesel obtained from the microalgal biomasses in OPRs 1 and 3 were 34.93\% and 32.85\%, respectively; total monounsaturated fatty acids (C16:1 and $\mathrm{C} 18: 1$ ) were $32.40 \%$ and $31.64 \%$, respectively; and polyunsaturated fatty acids (including C18:3) were $32.68 \%$ and $35.50 \%$, respectively. Fuel properties determined by empirical equations were within the limits of biodiesel standards ASTM D6751 and EN 14214. Culture solutions with or without microalgal biomasses enhanced 
the environmental adaptation ability of soybean plants, increasing their seed production. Therefore, microalgal biomass produced through mass cultivation is excellent feedstock for producing high-quality biodiesel and biofertilizer. 


\section{Assessment of biomass potentials of microalgal communities 2 in open pond raceways using mass cultivation}

3

4 5

6

22

23

24

25

26

27

28

29

30

31

32

33
Seung-Woo Jo ${ }^{1}$, Jeong-Mi Do ${ }^{2,3}$, Ho Na ${ }^{2,3}$, Ji Won Hong ${ }^{4}$, Il-Sup Kim ${ }^{5}$, Ho-Sung Yoon ${ }^{1,2,3,5}$ *

${ }^{1}$ Department of Energy Science, Kyungpook National University, Daegu 41566, Korea

${ }^{2}$ Department of Biology, Kyungpook National University, Daegu 41566, Korea

${ }^{3}$ School of Life Sciences, BK21 Plus KNU Creative BioResearch Group, Kyungpook National

University, Daegu 41566, Korea

${ }^{4}$ Department of Hydrogen and Renewable Energy, Kyungpook National University, Daegu 41566, Korea

${ }^{5}$ Advanced Bio-resource Research Center, Kyungpook National University, Daegu 41566, Korea

*Corresponding authors:

Il-Sup Kim, Ho-Sung Yoon

80 Daehak-ro, Buk-gu, Daegu, 41566, Republic of Korea

E-mail address: 92kis@hanmail.net (Il-Sup Kim), hsy@knu.ac.kr (Ho-Sung Yoon)

西




\section{Abstract}

35

36

37

38

39

40

41

42

43

44

45

46

47

48

49

50

51

52

53

54

55

56

57

58

59

60

61

62

63

64

65

\section{9}

0

Metagenome studies have provided us with insight into the complex interactions of microorganisms with their environments and hosts. Few studies have focused on microalgaeassociated metagenomes, and no study has addressed aquatic microalgae and their bacterial communities in open pond raceways (OPRs). This study explored the possibility of using microalgal biomasses from OPRs for biodiesel and biofertilizer production. The fatty acid profiles of the biomasses and the physical and chemical properties of derived fuels were evaluated. In addition, the phenotype-based environmental adaptation ability of soybean plants was assessed. The growth rate, biomass, and lipid productivity of microalgae were also examined during mass cultivation from April to November 2017. Metagenomics analysis using MiSeq identified 127 eukaryotic phylotypes following mass cultivation with (OPR 1) or without (OPR 3) a semitransparent film. Of these, $\sim 80$ phylotypes were found in both OPRs, while 23 and 24 phylotypes were identified in OPRs 1 and 3, respectively. The phylotypes belonged to various genera, such as Desmodesmus, Pseudopediastrum, Tetradesmus, and Chlorella, of which, the dominant microalgal species was Desmodesmus sp.. On average, OPRs 1 and 3 produced $\sim 8$ and $9.9 \mathrm{~g} \cdot \mathrm{m}^{-2} \cdot \mathrm{d}^{-1}\left(0.307\right.$ and $\left.0.309 \mathrm{DW} \cdot \mathrm{L}^{-1}\right)$ of total biomass, respectively, of which 14.0 and 13.3 $w t \%$ respectively, was lipid content. Fatty acid profiling revealed that total saturated fatty acids (mainly $\mathrm{C} 16: 0$ ) of biodiesel obtained from the microalgal biomasses in OPRs 1 and 3 were 34.93\% and 32.85\%, respectively; total monounsaturated fatty acids (C16:1 and C18:1) were 32.40\% and $31.64 \%$, respectively; and polyunsaturated fatty acids (including C18:3) were $32.68 \%$ and 35.50\%, respectively. Fuel properties determined by empirical equations were within the limits of biodiesel standards ASTM D6751 and EN 14214. Culture solutions with or without microalgal biomasses enhanced the environmental adaptation ability of soybean plants, increasing their seed production. Therefore, microalgal biomass produced through mass cultivation is excellent feedstock for producing high-quality biodiesel and biofertilizer. 61 


\section{Introduction}

67 Microalgae, which have evolved over a long period, are biologically diverse organisms that are

68 highly valuable for academic and industrial fields. Microalgae have high cellular lipid content and 69 so have distinct characteristics that may be used for biodiesel production or for the production of various other useful substances, such as valuable unsaturated fatty acids (UFAs), proteins, vitamins, and carotenoid secondary metabolites (Ren et al., 2017). Therefore, microalgae are increasingly used to produce high-value products and bioactive substances in a wide spectrum of fields ranging from sustainable energy to healthcare (Jebali et al., 2019). Global microalgal research can be considered the next-generation industry that will spearhead the growth of a green and low-carbon era (Bell et al., 2016).

Microalgae can generate large amounts of carbon-rich fatty acids from $\mathrm{CO}_{2}$ and grow fast in poor-quality waters or on non-arable lands without depleting food resources, so they are effective biofuel sources (Simas-Rodrigues et al., 2015; Faried et al., 2017; Ren et al., 2017). Microalgal strains of industrial value are found by either characterizing natural strains or establishing artificial strains through genetic manipulation. Isolating of new microalgal strains from the environment enables the finding of new strains that have unique physiological features and are promising biofuel sources (Abou-Shanab et al., 2011). This approach is effective because of myriads of uncharacterized microalgal strains in nature. However, artificial strain improvement through genetic engineering depends exclusively on the microalgal genetic information available (Cheng et al., 2019). Unfortunately, despite the industrial importance of microalgae, research on microalgal genetic engineering is limited compared to similar research on other organisms $(\mathrm{Ng}$ et al., 2017). Microalgal genetic engineering technologies have been fully established only for Chlamydomonas reinhardtii (Young \& Purton, 2016). Although other microalgal strains have been successfully transformed, these are usually one-time cases with low reproducibility (Siddiqui et al., 2019). In addition, native isolates are well adapted to local conditions and exhibit better performance and robustness (Alishah Aratboni et al., 2019). Therefore, for large-scale industrial uses of microalgae, it is necessary to establish a microalgal mass cultivation system, such as the open pond raceway (OPR), using indigenous microalgal species instead of engineered strains.

To realize the potential of microalgae, improvements are required in cost, productivity, and sustainability (Dahlin et al., 2018). To scale up production at lower costs, open pond systems coupled with fresh water or wastewater are a viable alternative (Bell et al., 2016). These systems 
97 are operated in semi-continuous or continuous mode to meet industrial production standards by 98 maximizing both biomass and lipid productivities, while ensuring the industrial suitability of the 99 microalga-derived fatty acids (Song et al., 2013). However, although outdoor productivity is often 100 less than the laboratory yield because of the extreme dynamics of environmental conditions, such 101 as water temperature and light intensity, studies on identifying optimal strains have rarely 102 investigated these criteria in semi-continuous or continuous cultures (Dahlin et al., 2018). 103 Recently, several studies questioned the sustainability of biofuel production from freshwater 104 species because itis uneconomical (Chisti, 2013). Because of these limitations, most studies on 105 microalgae are conducted in closed photobioreactors (Ren et al., 2017). However, an open pond

106 107 108

109

110

111

112

113

114

115

116

117

118

119

120

121

122

123

124

125

126

127 system is still needed in order to produce bioenergy as an alternative to fossil fuel.

In industrial-scale open pond cultivation with fresh water, many environmental (light and temperature), operational ( $\mathrm{pH}, \mathrm{CO}_{2}$, and nutrients), and biological (bacteria and fungi) parameters affect microalgal diversity and productivity, in turn affecting biomass quality and quantity (Cho et al., 2015). Therefore, open pond systems are prone to colonization by environmental microbes and may contain numerous distinct taxa (El-Sheekh et al., 2019). In the microalgal-based biofuel field, maintaining the integrity of the dominant microalgal species is mandatory, so there is a lot of uncertainty around biofuel production through freshwater systems (Roccuzzo, Beckerman \& Pandhal, 2016). In addition, the feasibility of maintaining dominant microalgal communities in fresh water-dependent ponds and the factors involved thereof are unclear (Park, Craggs \& Shilton, 2013). Undesirable colonization can be controlled by using locally adapted microalgae observed in natural ecosystems, and extensive studies have been conducted to probe locally isolated microalgae strains for their potential to be used in biofuel production (Rodolfi et al., 2009).

Metagenome technologies are powerful tools for analyzing complex microbial communities and have led to a tremendous increase in the knowledge of the functions, protein families, biotechnology, and ecology of microbial communities (Hugenholtz et al., 1998; Krohn-Molt et al., 2017). Metagenome studies have provided us with insight into the complex interactions of microorganisms with their environments and hosts (Krohn-Molt et al., 2017). Surprisingly, few studies have focused on microalgae-associated metagenomes (Krohn-Molt et al., 2017; Sambles et al., 2017), and no study has addressed aquatic microalgae and their bacterial communities in OPRs. However, the microalgal community based on phylogenetic and metagenomic diversity is growing. 
128

129

130

131

132

133

134

135

136

137

138

139

140

141

142 A microalgal semi-continuous mass cultivation system comprising two OPRs $\left(\sim 675.0 \mathrm{~m}^{2}\right)$ with

143 (OPR 1) or without (OPR 3) a semitransparent film at Chilgok-gun Agricultural Technology 144 Center $\left(36^{\circ} 02^{\prime} 18.91^{\prime \prime} \mathrm{N}, 128^{\circ} 22^{\prime} 57.7^{\prime \prime} \mathrm{E}\right)$, Korea, was operated to monitor the ecological system

145 146

147

148

149

150

151

152

153

154

155

156

157

158

This study investigated the effect of various factors on the diversity and productivity of an indigenous microalgal community in OPRs with (OPR 1) or without (OPR 3) a semitransparent film through three seasons. We modeled the biodiversity of a microalgal mass cultivation system by considering environmental factors, such as water temperature, intra- and interspecies competition in the microalgal community, and the abundance of other species, including cyanobacteria. We measured biomass-based lipid production in fresh water dependent OPRs operated during mass cultivation from April to November 2017. To identify locally adapted microalgal strains, we examined and statistically analyzed various environmental (meteorological and nutritional), biological (algal and cyanobacterial diversity), and physiochemical (fatty acid profile and biodiesel quality) parameters. Our findings may facilitate biofuel and biofertilizer production from freshwater system biomasses.

\section{Materials and methods}

\section{Operation of an OPR system} and biodiversity in microalgae-dependent mode under natural environmental conditions. The mass cultivation period was from April 1 to November 30, 2017. OPRs used natural sunlight. We supplemented 236 tons of groundwater with Eco-Sol (nitrogen:phosphorus:potassium = 25:9:18; Farm Hannong, Ulsan, Korea) as a commercial water-soluble fertilizer to produce a final concentration of $10.0-18.0 \mathrm{mg} \cdot \mathrm{L}^{-1}$ total nitrogen $(\mathrm{TN})$ and $2.0-3.0 \mathrm{mg} \cdot \mathrm{L}^{-1}$ total phosphorus (TP). Next, we injected $10 \%$ of $\mathrm{CO}_{2}$ in air at a flow rate of $10 \mathrm{~L} \cdot \mathrm{min}^{-1}$ in both OPRs using a venturi system during daylight hours (Hong et al., 2017). The OPR temperature and $\mathrm{pH}$ were measured every $3 \mathrm{~h}$ using a WQC-24 portable multiparameter water quality meter (Multi Measuring Instruments Co. Ltd., Tokyo, Japan).

\section{Microalgae mass cultivation}

Indigenous microalgae from earlier cultivation periods were used. Briefly, Desmodesmus sp., the dominant species grown in OPRs, was inoculated, and species succession was monitored at morphological and molecular levels. Semi-continuous cultivation was conducted at a velocity of 
$15925-30 \mathrm{~cm} \cdot \mathrm{s}^{-1}$. Next, we harvested 155 tons (approximately two-thirds of the microalgal culture

160 from each raceway and replaced it with the same volume of underground water with appropriate 161 nutrient levels; the remaining culture was used as a seed. The mass cultivation was continuously 162 recycled throughout the study. When TN and TP were almost depleted and the optical density 163 (OD) and total biomass reached their maximum values, the culture was harvested. TN and TP 164 levels were quantitated using HS-TN(CA)-L and HS-TP-L water test kits (Humas, Daejeon, 165 Korea), and OD was measured using a spectrophotometer (X-ma 1200V; Human Corp., Seoul, 166 Korea) at a wavelength of at $680 \mathrm{~nm}$. The total biomass was dried in a dry oven and weighed. 167 Finally, to observe morphological changes, the microalgal cultures were sampled every 3 days and 168 inspected at $400 \times$ magnification under an Eclipse E100 microscope (Nikon Instruments Inc., 169 Tokyo, Japan).

170

\section{MiSeq-based microalgal diversity}

172 To determine mock communities, we screened OPRs for the presence of Acutodesmus sp. 173 KNUA038, Chlamydomonas sp. KNUA023, Chlamydomonas sp. KNUA040, Chlorella sp. 174 KNUA027, Desmodesmus sp. KNUA024, Pseudopediastrum sp. KNUA039, and Scenedesmus 175 obliquus KNUA019 by sequencing 18S ribosomal RNA(rRNA) V4 and V8-V9 regions, as 176 previously described (Bradley, Ian M, Pinto, Ameet J, Guest, 2016). We also confirmed microalgal 177 identification by using the Basic Local Alignment Search Tool (BLAST) against the National 178 Center for Biotechnology Information (NCBI) GenBank database.

179 Next, we extracted genomic DNA (gDNA) from the harvested biomass using a DNeasy 180 Plant Mini kit (Qiagen, Hilden, Germany) and purified it using a Wizard DNA Clean-Up System 181 (Promega, Madison, WI, USA) according to the manufacturers' instructions. Then, 16S and 18S 182 rRNA genes were used to identify cyanobacteria and microalgae, respectively, within the OPRs. 183 Each sequencing sample was prepared in accordance with Illumina 16S and 18S metagenomic 184 sequencing library protocols, as previously described (de Muinck et al., 2017; Kim et al., 2017). 185 Briefly, for 16S rRNA, the internal transcribed spacer 2 (ITS2) region was amplified using PCR 186 with the ITS3/ITS4 primer set (de Muinck et al., 2017; Kim et al., 2017). The 18S protocol was 187 designed to broadly recognize eukaryotes, favoring microbial eukaryotic lineages. The primers 188 were based on a previous report (Amaral-Zettler et al., 2009) and designed to be used with the 189 Illumina MiSeq platform (Bradley, Ian M, Pinto, Ameet J, Guest, 2016). The 18S libraries on 
190 MiSeq were run, as previously described (Caporaso et al., 2012), and PCR amplicons derived from 191 the conserved V8-V9 region by using the Mi1422F/Mi1510R primer pair were sequenced. Table 192 S1 shows the primer sets overhanging the pre-adapter and sequencing adapter. The outlines of the $19316 \mathrm{~S}$ and $18 \mathrm{~S}$ protocols were the same. Sequences were processed and data mining performed, as 194 previously described (Kozich et al., 2013; Bradley, Ian M, Pinto, Ameet J, Guest, 2016). Finally, 195 the consensus taxonomy of the operational taxonomic unit (OTU) was constructed using Silva 196 v119 taxonomy information (Ondov, Bergman \& Phillippy, 2011).

197

198

Microalgal biomass characterization

199 First, the harvested biomass was freeze-dried, pulverized using a mortar and pestle, and sieved 200 through an ASTM No. 230 mesh (pore size $=63 \mu \mathrm{m}$ ). Next, the total lipid content was determined 201 using a the sulfo-phospho-vanillin colorimetric method, as previously described with 202 modifications (Mishra et al., 2014). Proximate analysis was performed to measure ash content 203 using a DTG-60A thermal analyzer (Shimadzu, Kyoto, Japan) and platinum pans containing 10 $204 \mathrm{mg}$ of each sample or $30 \mathrm{mg}$ of $\alpha$-alumina $\left(\alpha-\mathrm{Al}_{2} \mathrm{O}_{3}\right)$ powder (Shimadzu) as a reference. Nitrogen $205\left(>99.999 \%, \mathrm{~N}_{2}\right)$ was supplied as the carrier gas at a rate of $25 \mathrm{~mL} \cdot \mathrm{min}^{-1}$ to prevent oxidation of 206 the microalgae powder. The samples were heated from $50{ }^{\circ} \mathrm{C}$ to $900{ }^{\circ} \mathrm{C}$ at a rate of $10{ }^{\circ} \mathrm{C} \cdot \mathrm{min}^{-1}$. 207 Thermogravimetric analysis (TGA) data were obtained using ta60 ver. 2.21 software (Shimadzu) 208 according to the manufacturer's instructions. Ultimate analysis was performed using a Flash 2000 209 elemental analyzer (Thermo Fisher Scientific, Milan, Italy) to determine the carbon (C), hydrogen $210(\mathrm{H})$, nitrogen $(\mathrm{N})$, and sulfur $(\mathrm{S})$ content, and the oxygen $(\mathrm{O})$ content was calculated by subtracting 211 the ash and CHNS content from the total. The calorific value (CV, also known as higher heating 212 value [HHV]) was estimated using the following equation developed by Friedl et al. (2005):

213

214

215

216

217

218

219

220

$$
\mathrm{CV}=\left\{3.55 \mathrm{C}^{2}-232 \mathrm{C}-2,230 \mathrm{H}+51.2 \mathrm{C} \times \mathrm{H}+131 \mathrm{~N}+20,600(\mathrm{MJ} / \mathrm{kg})\right\}
$$

\section{Gas chromatography-mass spectrometry analysis}

Lipid extraction was performed as previously described (Breuer et al., 2013). The fatty acid methyl ester (FAME) composition was analyzed using a 7890A gas chromatograph equipped with a 5975C mass selective detector (Agilent, Santa Clara, CA, USA). Gas chromatography (GC) runs were performed using a DB-FFAP column (30 m, $250 \mu \mathrm{m}$ ID, $0.25 \mu \mathrm{m}$ film thickness; Agilent). 
221 The initial oven temperature of the gas chromatograph was set to $50{ }^{\circ} \mathrm{C}$ and maintained for $1 \mathrm{~min}$; 222 subsequently, it was increased first to $200{ }^{\circ} \mathrm{C}$ at a rate of $10{ }^{\circ} \mathrm{C} \cdot \mathrm{min}^{-1}$ for $30 \mathrm{~min}$ and then to 240 $223{ }^{\circ} \mathrm{C}$ at a rate of $10{ }^{\circ} \mathrm{C} \cdot \mathrm{min}^{-1}$, which was maintained for $20 \mathrm{~min}$. The injection volume was $1 \mu \mathrm{L}$, 224 with a split ratio of 20: 1 . Helium was used as a carrier gas at a constant flow rate of $1 \mathrm{~mL} \mathrm{~min}{ }^{-1}$. 225 The mass spectrometry (MS) parameters were as follows: injector and source temperatures of 250 $226{ }^{\circ} \mathrm{C}$ and $230{ }^{\circ} \mathrm{C}$, respectively; electron impact mode at an acceleration voltage of $70 \mathrm{eV}$ for sample 227 ionization; and acquisition range of 50-550 m/z. Compound identification was performed by 228 matching the mass spectra with those in Wiley/NBS libraries; matches $>90 \%$ were considered 229 valid.

230

231 Biodiesel quality assessment

232 The following physical parameters were measured to assess biodiesel quality: saponification value 233 (SV), iodine value (IV), degree of unsaturation (DU), cetane number (CN), long-chain saturated 234 factor (LCSF), and cold filter plugging point (CFPP). The parameters were quantitated on the basis 235 of the fatty acid compositions using the following empirical equations, as previously described 236 (Ramos et al., 2009):

237

238

239

240

241

242

243

244

245

246

where $D, M$, and $N$ denote the number of double bonds, average molecular mass, and weight 247 percent $(\mathrm{wt} \%)$ of each fatty acid, respectively; MUFA refers to monounsaturated fatty acid; and 248 PUFA refers to polyunsaturated fatty acid. C16:0, C18:0, C20:0, and C22:0 are also in wt\%.

Biological enhancer assay in soybean plants 
251 First, soybean seeds (Daewon) were sown in cultivation soil, germinated at $30{ }^{\circ} \mathrm{C}$ for $\sim 7$ days in a 252 growth chamber $\left(70-100 \mu \mathrm{mol} \mathrm{m} \mathrm{m}^{-2} \cdot \mathrm{s}^{-1}\right)$ in a $14 \mathrm{~h} / 10 \mathrm{~h}$ dark cycle, at $60 \%$ humidity, and grown to 253 the V2 stage in the same incubator. Next, 15 soybean seedlings were transplanted to a large pot 30 $254 \mathrm{~cm}$ in diameter and then cultivated near a mass culture open pond system. Subsequently, we 255 applied the following treatments to the soybeans, with the solutions applied every 3 days:

256

257 1. The control pot was supplemented with $1 \mathrm{~L}$ of groundwater.

258 2. The experimental pot was supplemented with $1 \mathrm{~L}$ of the eco-sol medium as a soil drench.

259 3. The supernatant (1 L) of the microalgal culture was collected by centrifugation at 4,000 rpm 260 for $20 \mathrm{~min}$ at $20^{\circ} \mathrm{C}$ and mixed with the eco-sol medium as a soil drench.

261 4. The culture solution (1 L) containing microalgal biomass and the supernatant as a soil drench. 262 5. The pot with soybean plants was sprayed with $1 \mathrm{~L}$ of microalga-free supernatant.

263

264 The soybean plants' environmental adaptation was assessed by monitoring the plant phenotype, 265 and soybean productivity was measured by examining seed maturation and the pod weight per 266 seedling.

267

268

\section{Statistical analysis}

269

All experiments were performed in at least triplicate. Data were shown as the average of triplicates,

270 and error bars represented the standard deviation. $P<0.05$ was considered statistically significant.

271

\section{Results}

\section{Biodiversity of mass cultivation in open pond raceways}

\section{Establishment of MiSeq-based qualitative verification}

275 First, we examined the reported primer sets to determine whether the microalgal communitiy 276 comprising the seven known microalgal species (Acutodesmus sp. KNUA038, Chlamydomonas sp. KNUA023, Chlamydomonas sp. KNUA040, Chlorella sp. KNUA027, Desmodesmus sp. 278 KNUA024, Pseudopediastrum sp. KNUA039, and Scenedesmus obliquus KNUA019) could be 279 effectively characterized by high-throughput sequencing (HTS). PCR amplification with primers 280 for actin, $r b c L$, and 18S rRNA V4, V8-V9, and V9 regions yielded 180-650 bp amplicons from 281 the pooled gDNA isolated analyzed samples (Fig. S1, and Data S1). We obtained an amplicon of 
$282 \sim 610$ bp with $r b c L$ primers 28S2F/28S2R (Fig. S1B). However, no amplicon was detected in 283 analyzed samples with actin primers (Fig. S1A).

284 Next, we introduced various regions of the 18S rRNA gene into HTS-based comparative 285 analysis. Of them, V4 and V8-V9 regions were significant, and the taxonomic groups for the V8286 V9 region showed higher concordance rates compared to the V4 region. The V4 region failed to 287 reliably capture two of the seven microalgal species included in this study (Acutodesmus sp. 288 KNUA0038 [accession no. KT883908] and Scenedesmus sp. KNUA019 [unregistered]), while the 289 V8-V9 region accurately represented the mean relative abundance (Tables S2 and S3). However, 290 the V9 region was too short $(<200$ nucleotides [nt]) to allow overlap between forward and reverse 291 reads in the Illumina Miseq platform (250-300-nt single read length, resulting in 450-500-nt-long 292 combined reads with 50-150 bp overlaps) (Bradley, Ian M, Pinto, Ameet J, Guest, 2016). Results 293 showed that the V8-V9 region of the 18S rRNA gene is more effective for HTS compared to other 294 candidate genes because 400-500 bp amplicons are required. Figure S2A shows schematic 295 diagrams showing the biodiversity analysis.

296

297

\section{Changes in environmental factors and growth parameter during open-pond mass cultivation}

We analyzed environmental conditions in OPRs 1 and 3 during mass cultivation from April to 299 November 2017 because the water surface was frozen in OPR 3 (without a semitransparent film) 300 from December 2017 to February 2018 but not in OPR 1 (with the same semitransparent film) (Fig. S2B and Data S2). The mean water temperature in spring (April-May), summer (June302 August), and the fall (September-November), was $17.4{ }^{\circ} \mathrm{C}, 25.4{ }^{\circ} \mathrm{C}$, and $14.1^{\circ} \mathrm{C}$, respectively 303 (Fig. 1A). Although we observed no differences between OPRs 1 and 3, the temperature of OPR 1 was higher compared to OPR 3 during mass cultivation, except for summer. In addition, $\mathrm{pH}$ was 305 neutral to heavy alkaline (7.2-10.4), becoming increasingly neutral with a gradual increase in 306 water temperature (Fig. 1B).

With regard to dissolved nutrients, TN and TP levels were strongly depleted in summer 308 compared to spring and the fall, concurrent with a rapid increase in total biomass and lipid levels. 309 Compared to initial TN levels $\left(\sim 17 \mathrm{mg} \cdot \mathrm{L}^{-1}\right), \sim 13.57-16.69 \mathrm{mg} \cdot \mathrm{L}^{-1}$ was removed in summer and $\sim 10.02-13.21 \mathrm{mg} \cdot \mathrm{L}^{-1}$ in spring and the fall. Initial TP levels were $2.45-2.63 \mathrm{mg} \cdot \mathrm{L}^{-1}, 2.35-2.62$ $311 \mathrm{mg} \cdot \mathrm{L}^{-1}$ in summer, and $1.47-2.22 \mathrm{mg} \cdot \mathrm{L}^{-1}$ in spring and the fall (Fig. 1C, and Data S2). Overall, $312 \mathrm{TN}$ and TP consumption was $12.87 \mathrm{mg} \cdot \mathrm{L}^{-1}(86.2 \%)$ and $2.26 \mathrm{mg} \cdot \mathrm{L}^{-1}(96.3 \%)$, respectively, in 
313 OPR 1 but $13.14 \mathrm{mg} \cdot \mathrm{L}^{-1}(90.1 \%)$ and $2.10 \mathrm{mg} \cdot \mathrm{L}^{-1}(93.5 \%)$ in OPR 3, which confirmed the higher 314 nutrient removal rate in TP compared to TN.

315 We also investigated the relationship between nutrient consumption and biomass 316 productivity. Total biomass was based on growth kinetics measured from the OD and DW. The 317 absorbance and DW of OPR \#3 were higher compared to OPR 1 in June-August 2017, with the 318 highest difference in summer, when water temperature increased. OPR 3 had a maximum biomass 319 production of $17.6 \mathrm{~g} \cdot \mathrm{m}^{-2} \cdot \mathrm{d}^{-1}$, while OPR 1 in the greenhouse had a maximum microalgal biomass 320 production of $13.3 \mathrm{~g} \cdot \mathrm{m}^{-2} \cdot \mathrm{d}^{-1}$ (Fig. 1E and Data S2). OPRs 1 and 3 had a mean total microalgal 321 biomass production of $\sim 8.6-9.9 \mathrm{~g} \cdot \mathrm{m}^{-2} \cdot \mathrm{d}^{-1}$, corresponding to $0.307-0.309 \mathrm{DW} \cdot \mathrm{L}^{-1}$ (Figs. 1D-F and 322 Data S2).

323

Overview of MiSeq-based microalgal community during mass cultivation

325 We monitored the microalgal community using MiSeq with DNA isolated from the pooled 326 microalgal biomass during mass cultivation from April to November 2017. PCR products were visualized to identify contaminated samples (Fig. S2C) and then used in MiSeq. MiSeq analysis produced results for the OTU and Shannon $\left(H^{\prime}\right)$ and Simpson $(D)$ indices (Data S3). The number of OTUs in OPR 1 and 3 significantly increased in the fall compared to spring and summer, although the two OPRs showed a slight difference. The $H^{\prime}$ index in July-November 2017 was within the typical range of 1.5-3.5, as previously reported (Bradley, Ian M, Pinto, Ameet J, Guest, 2016), and in April-June 2017 was rarely < 1.5. During the testing period, the $D$ index, the most common dominance parameter, decreased with time, indicating that diversity increases with regard to evenness (Fig. S3). Richness and evenness are confounded in the $H^{\prime}$ index, so many biodiversity researchers prefer to use two indices for comparative studies, combining a direct estimate of species richness (i.e., the total number of species in the community) with some measurement of dominance or evenness (Caporaso et al., 2010).

Microalgal succession during mass cultivation

340 The following eukaryotic organisms, including microalgae, were identified in OPR 1: 341 Desmodesmus sp. (62\%), Heterocypris sp. (5\%), Amoeboaphelidium sp. (4\%), Pseudodifflugia cf. 342 (2\%), Chlorella sp. (1\%), Coelastrum pseudomicroporum (1\%), Pseudopediastrum integrum 343 (1\%), Chlamydomonadales sp. (0.9\%), Tetradesmus obliquus (0.8\%), Hariotina reticulate ( $0.3 \%)$, 
344 Scenedesmus sp. (0.1\%), and others (18\%), such as uncultured eukaryotes (Fig. 2). The following 345 species were identified in OPR 3: Desmodesmus sp. (74\%), T. obliquus $(1 \%)$, and others $(22 \%)$ 346 (Figs. 2 and S4, and Data S3 and S4). Although a greater number of microalgal species were found 347 in OPR 1, the highly dominant microalgal species in both OPRs 1 and 3 was Desmodesmus sp. 348 (Fig. 2). The Desmodesmus sp. population of OPR 3 was 12\% higher than that of OPR 1.

349 As water temperature in OPR 1 and 3 increased in spring (Fig. 1A), some green microalgae 350 (e.g., Desmodesmus sp. and T. obliquus) showed a change in their taxonomic ranks (Fig. 3). The 351 microalgal bloom period in the spring was $\sim 3-4$ weeks because of competition within the 352 cultivation tank, and the effect of increased numbers of other eukaryotic organisms switched every 353 2-3 weeks (Fig. S4). In late spring, green microalgae (Chlorophyta), such as Desmodesmus sp., 354 proliferated rapidly as water temperature increased, becoming the dominant species (Fig. S7A-D). 355 In summer, various species, including green microalgae, such as Desmodesmus sp., Chlorella sp., C. pseudomicroporum, and P. integrum, proliferated more vigorously in OPR 1 compared to OPR 3 (Figs. 3, S5A-E, and S8). In addition, the proportion of Heterocypris species, known as Ostracoda, increased to 33\% in OPR 1 in summer (August) before disappearing after the fall when water temperature decreased (Figs. S1A and S9A, and Data S4). In OPR 3, Nucleariidae was abundant in summer but disappeared after the fall (Figs. 3 and S9B). In the fall, various species that were highly abundant in summer disappeared because of low water temperatures (Figs. 1A and S9C-D, and S10). Desmodesmus sp. became dominant again in OPRs 1 and 3, and the proportions of Coelastrum sp., Golenkinia longispicula, and Micractinium sp. increased in OPR 1. Chlorella miniata appeared in the fall as well (Figs. 3 and S10A). Overall, our results indicated that the difference between ecologically stabilized (OPR 3) and artificial (OPR 1) cultivation systems can be distinguished by their microalgal flora contents and that Desmodesmus sp. is a potential species for mass cultivation, especially in an open pond system.

368

370 We identified 26 cyanobacteria species (Figs. S11 and S12, and Data S5 and S6). Of these, 371 Cyanobium gracile frequently appeared in both OPR 1 and 3 in spring and summer, while 372 Foliisarcina bertiogensis, Spirulina major, Cyanobacterium aponinum, and Microcystis 373 aeruginosa bloomed in the fall, but their populations were higher in OPR 1 compared to OPR 3 , and Synechococcus elongatus and Calothrix desertica were identified only in OPR 3 in the fall 
375 (Fig. S12F-H). The relative abundance of other cyanobacterial species identified was $<1 \%$ (Fig. 376 S14). Overall, the number of emerging microalgal species in OPRs 1 and 3 was high in summer 377 and low in spring and the fall, consistent with cyanobacterial species emergence, which are highly 378 abundant in summer. In addition, three dinoflagellate and one cryptomonad species were also 379 identified. In wastewater treatment coupled with biofuel applications, cyanobacteria continue to 380 dominate during the fall and winter, which has an overarching influence on microalgal diversity 381 and microalgal biomass (Cho et al., 2015). Therefore, we need a good understanding of beneficial 382 interactions between microalgae and other organisms, including cyanobacteria, for exploring the 383 biotechnological applications of microalgae-based biomasses.

384

\section{Proximate and ultimate analyses}

386

387

388

389

390

391

392

393

394

395

396

397

398

399

400

401

402

403

404

405

A higher percentage of bioenergy parameters such as volatile matter $(\mathrm{VM} ;>80 \%)$ is advantageous for biofuel production and biodiesel quality, so we performed quantitative estimation of the microalgal biomass using proximate and ultimate analyses (Awaluddin et al., 2016). We identified very small differences between OPRs 1 and 3 during culture. In proximate results, moisture, VM, and ash contents were $4.2-8.3,71.5-84.0$, and $10.5-21.7 \mathrm{wt} \%$, respectively. In addition, moisture levels were slightly higher in spring and the fall in OPR 1, although it was difficult to determine a regular pattern for moisture in OPRs 1 and 3 . The increased moisture value in spring gradually decreased in summer and again increased in the fall, which was observed in both OPRs 1 and 3. The VM content was the highest in summer and the fall, with OPR 1 being $2 \%-3 \%$ higher than OPR 3, while the ash content reached the highest level in spring, with OPR 3 being $\sim 4 \%-5 \%$ higher than OPR 1. Overall, the mean weight percentage values of moisture, VM, and ash content were $6.68,79.73$, and 13.57, respectively, in OPR 1 and 6.10,77.42, and 16.48, respectively, in OPR 3 (Table 1).

In ultimate, carbon, nitrogen, and hydrogen levels were relatively higher in summer and the fall relative to levels in spring and higher in OPR 1 compared to OPR 3, consistent with the increased water temperature during culture. The sulfur and oxygen content were also higher in OPR 1 compared to OPR 3. The mean weight percentage values of carbon, hydrogen, nitrogen, sulfur, and oxygen (CHNSO) were 43.22, 6.23, 6.23, 0.46, and 30.31, respectively, in OPR 1 and $41.50,5.86,5.62,0.41$, and 26.77, respectively, in OPR 3. The CV was higher in summer and the fall compared to spring and higher in OPR 1 compared to OPR 3 (Table 1). The mean CV of OPR 
4061 and 3 was 19.51 and $18.43 \mathrm{MJ} \cdot \mathrm{kg}^{-1}$, respectively, which are higher compared to the land plant 407 biomass (18.4 MJ $\mathrm{kg}^{-1}$ ) (Ross et al., 2008). Therefore, the microalgal biomass grown in an open 408 pond using mass cultivation, especially OPR 1, can have the potential to be used for producing 409 biofuels of the desired quality.

410

411 Fatty acid profiles

412 Figure 4 shows the fatty acid compositions of the microalgal biomasses in OPRs 1 and 3 during 413 mass cultivation from April to November 2017. The major fatty acids analyzed were myristic 414 (C14:0), palmitic (C16:0), palmitoleic (C16:1), palmitidonic (C16:4), oleic (C18:1), linolelaidic 415 (C18:2), and linolenic (C18:3) acids. C16:0 was the most abundant fatty acid in both OPRs 416 throughout the culture period $(21.9 \%-36.5 \%)$, while C18:1 was the second-most abundant fatty 417 acid in OPR 1, which increased from spring to summer when water temperature was high and then 418 decreased in the fall. In contrast, C18:1 increased in OPR 3 in spring and the fall and slightly 419 decreased in summer (range 10.1\%-28.6\%). In addition, the C16:1 ratio reached a maximum of $42025.6 \%$ in both OPRs, showing a similar pattern as C16:0 in OPR 1 and gradually decreasing with 421 time in OPR 3. The staple lipid composition for biodiesel production was better in OPR 3 422 compared to OPR 1, except for C16:1. In addition, we found traces of other fatty acids and no 423 significant difference between OPRs 1 and 3. However, we identified arachidonic acid (C20:4; $4240.19 \%)$ and eicosapentaenoic acid (C20:5; 1.38\%) only in OPR 1 and behenic acid (C22:0; 0.19\%) 425 in OPR 3. Also, the mean C16:0, C18:1, and C18:2 composition of the biodiesel was 24.5\%, $42617.0 \%$, and $6.1 \%$, respectively, in OPR $1(47.6 \%$ in total) and $24.2 \%, 22.0 \%$, and $5.8 \%$, 427 respectively, in OPR 3 (52\% in total). The total UFA concentration in the biodiesels derived from 428 OPR 1 and 3 was $65.1 \%$ and $67.2 \%$, respectively, approximately twice the saturated fatty acid 429 (SFA) concentrations (34.9\% and 32.8\%). Therefore, the microalgal biomass produced through 430 mass cultivation, especially OPR 3 with a high C18:1 content, has potential as feedstock for 431 producing biodiesel of the desired quality.

\section{Biodiesel quality evaluation}

434 The viscosity, ignition quality, oxidative stability, and cold flow of biodiesel are largely affected 435 by the structure of component fatty acid esters (Arguelles et al., 2018). Therefore, it is important 436 to develop a microalgal species with a suitable lipid composition for microalgae-based biodiesel 
437 production. In this study, we calculated fuel physicochemical properties using empirical equations 438 (based on fatty acid profile analysis) because proximate and ultimate analyses and fatty acid 439 profiling showed that mass-cultured biomass has the potential to be used in biofuel production 440 (Table 1 and Fig. 4). The parameters analyzed included SV, IV, DU, LCSF, CFPP, oxidation 441 stability, kinematic viscosity, and density. Fuel quality properties were also determined using 442 empirical equations and were within the limits of biodiesel standards ASTM D6751 and EN 14214. 443 The biodiesels derived from OPRs 1 and 3 had a low density $\left(0.87 \mathrm{~g} \cdot \mathrm{cm}^{-3}\right)$ and low kinematic 444 viscosity $\left(3.95 \mathrm{~mm}^{2} \cdot \mathrm{s}^{-1}\right)$. In addition, values of the other parameters were as follows: $\mathrm{CN}, 56.27$ 445 and 52.97, respectively; oxidation stability, 13.02 and $11.66 \mathrm{~h}$, respectively; CFPP, $-3.8^{\circ} \mathrm{C}$ and $4463.0^{\circ} \mathrm{C}$, respectively; and IV, $85.83 \mathrm{~g} \cdot \mathrm{I}_{2} \cdot(100 \mathrm{~g})^{-1}$ and $97.16 \mathrm{~g} \cdot \mathrm{I}_{2} \cdot(100 \mathrm{~g})^{-1}$ fat, respectively. The 447 mean SV, DU, and LCSF were 203.60, $62.75 \mathrm{wt} \%$, and $4.03 \mathrm{wt} \%$, respectively, in OPR 1 and $448201.83,69.37 \mathrm{wt} \%$, and $4.31 \mathrm{wt} \%$, respectively, in OPR 3 (Table 2).

449

450

451

452

\section{Possibility of microalgae as biological enhancers}

The microalgal biomasses in OPRs 1 and 3 had the potential of feedstock for biodiesel production. Microalgae have been used in various industries, such as biofuel, cosmetics, bioremediation, and biocontrol, so we examined the application of microalgae as bioenhancers in soybean plants (Ronga et al., 2019). As shown in Fig. 5A-P, the microalgal population biodiversity in 2018 was similar to that in 2017 during mass culture, with the dominant species being Desmosdesmus. Figure 5Q shows weather changes during the analyzed periods (July 20 to November 21, 2018). The most distinguishable environmental change was a gradual decrease in air temperature. We conducted environmental adaptation assessment at least twice with V2 stage soybean plants grown after seed germination. The microalgae bioenhancer ability was based on the phenotype and seed germination. The first assessment found that the group subjected to the microalgal biomass (1-4 and 1-5), clear solution (1-3), or spray (1-6) of OPR 1 showed improved growth development compared to control groups (1-1 and 1-2), while groups treated with the clear solution (3-3) or spray (3-6) of OPR 3 showed an improved phenotype compared to other groups (Figs. 6A-E and S13). In addition, the soybean plant seeds treated with cleared microalgal culture solutions, which included microalgal biomass (1-4 and 1-5), had better quality compared to other groups, resulting in increased pod seed weight (Figs. $6 \mathrm{~F}-\mathrm{H}$ and S13). Therefore, the microalgal biomasses and supernatants of mass cultures can be used as feedstock for producing biodiesels and biofertilizers, 
468 respectively.

469

\section{Discussion}

\section{Overview of the MiSeq-based microalgal community during mass cultivation}

472 In previous studies, MiSeq of the 18S rRNA V9 region has failed to determine some species or 473 their abundance in dinoflagellate-diatom mixtures simulated at different ratios (Guo, Sui \& Liu, 474 2016). Therefore, various universal primers against $18 \mathrm{~S}$ rRNA regions have been used to identify 475 microalgal species at the molecular level. Although actin is more suitable as a molecular marker 476 compared to the 18S rRNA gene for analyzing dinoflagellate communities (Guo, Sui \& Liu, 2016), 477 the 18S rRNA gene is more effective for HTS compared to other candidate genes because 400$478500 \mathrm{bp}$ amplicons are required (Fig. S1) (Ishaq \& Wright, 2014). In addition, various regions of 479 the 18S rRNA gene have been introduced into HTS-based comparative analysis. Of these, the V4 480 and V8-V9 regions are significant, and taxonomic groups for the V8-V9 region exhibit higher 481 concordance rates compared to the V4 region (Fig. S1). In general, microalgal communities are 482 mostly profiled through morphological identification, followed by qualitative/quantitative 483 assessment using DNA barcoding (Serrana et al., 2019). However, this method is not optimal for 484 monitoring microalgal biodiversity in OPRs because of interfering factors, such as the cultivation 485 cycle (month, season, and year) (Cheung, Allen \& Short, 2020). Metagenomic analysis based on 486 DNA barcoding (the V8-V9 region of the 18S rRNA gene) can be used for rapid, accurate, and 487 automatable identification of microalgal species and their precise abundances in microalgal 488 cultures of industrial interest.

\section{Changes in nutrient parameters during mass cultivation in open pond raceways}

491

492

493

494

495

496

497

498

With regard to weather changes and nutrient (e.g., nitrogen and phosphorus) consumption, the temperature of OPR 1 was higher compared to OPR 3 during the mass cultivation period except in summer. $\mathrm{pH}$ was neutral to heavy alkaline (7.2-10.4) and became increasingly neutral with a gradual increase in water temperature (Fig. 1B). TN and TP consumption was $12.87 \mathrm{mg} \cdot \mathrm{L}^{-1}$ $(86.2 \%)$ and $2.26 \mathrm{mg} \cdot \mathrm{L}^{-1}(96.3 \%)$, respectively, in OPR 1 and $13.14 \mathrm{mg} \cdot \mathrm{L}^{-1}(90.1 \%)$ and 2.10 $\mathrm{mg} \cdot \mathrm{L}^{-1}(93.5 \%)$, respectively, in OPR 3 (Fig. 1C), confirming a higher nutrient removal rate for TP compared to TN. Phosphorus plays an important role in microalgae cellular metabolism by

forming many structural and functional components required for growth and development (Znad 
499 et al., 2018). Naturally occurring mixed microalgae have been used for wastewater treatment under 500 OPR conditions. Posadas et al. (2015) showed in OPR cultivation of Scenedesmus sp. that 501 wastewater treatment is confirmed by the effect of the $\mathrm{CO}_{2}$ source. The TN and TP removal rates 502 were $74 \% \pm 14$ and $57 \% \pm 12$, respectively. In another study involving semi-continuous cultivation 503 of Chlorella sp., Scenedesmus sp., and Stigeoclonium sp., wastewater treatment showed a mean $504 \mathrm{TN}$ and TP removal rate of $76.3 \% \pm 4.0$ and $51.5 \% \pm 3.9$, respectively (Kim et al., 2018). 505

506

507

508

509

510

511

512

513

514

515

516

517

518

519

520

521

522

523

524

525

526

527

528

529

\section{Algal biomass productivity}

The DW of OPR 3 was higher compared to OPR 1 during June-August 2017, with the highest difference in summer, when water temperature increased. OPR 3 had a maximum biomass production of $17.6 \mathrm{~g} \cdot \mathrm{m}^{-2} \cdot \mathrm{d}^{-1}$, while OPR 1 in the greenhouse had a maximum biomass of 13.3 $\mathrm{g} \cdot \mathrm{m}^{-2} \cdot \mathrm{d}^{-1}$ (Fig. 1E). Under specific environmental conditions of Almería, Scenedesmus is consistently the dominant microalgal species in OPRs. In previous studies, biomass productivities ranged from $4 \pm 0 \mathrm{~g} \cdot \mathrm{m}^{-2} \cdot \mathrm{d}^{-1}$ in December to $17 \pm 1 \mathrm{~g} \cdot \mathrm{m}^{-2} \cdot \mathrm{d}^{-1}$ in July (Posadas et al., 2015). The two OPRs had a mean total biomass production of $\sim 8.6-9.9 \mathrm{~g} \cdot \mathrm{m}^{-2} \cdot \mathrm{d}^{-1}$, corresponding to $0.307-$ $0.309 \mathrm{DW} \cdot \mathrm{L}^{-1}$ (Fig. 1D-1F). The lower biomass production in OPR 1 was presumably because of the reduced light intensity caused by the greenhouse's semitransparent film, as previously reported (Giacomelli \& Roberts, 1993). Supplying Desmodesmus sp. F51 with inorganic carbon and nitrogen sources at a 1:1 ratio enhanced cell growth and improved biomass production up to 939 $\mathrm{mg} \cdot \mathrm{L}^{-1} \cdot \mathrm{d}^{-1}$ (Xie et al., 2017). Overall, biomass and DW values corresponded to nutrient consumption, highlighting the time when the water temperature was maintained at $20{ }^{\circ} \mathrm{C}-25{ }^{\circ} \mathrm{C}$, on average, because of the higher atmospheric temperatures from June to September. Microalgae had an optimum growth temperature of $20^{\circ} \mathrm{C}-25^{\circ} \mathrm{C}$ under normal conditions (Patel et al., 2019).

\section{Microalgal and cyanobacterial communities}

Although we found a large number of microalgal species, including Desmodesmus sp., Chlorella sp., T. obliquus, and P. integrum, in both OPRs 1 and 3 in a 9 month period, the microalgal species highly dominant in both OPRs was Desmodesmus sp.. The microalgal abundance of OPR 1 was greater compared to OPR 3. Seasonal changes in light conditions play an important role in sustaining species diversity in OPR systems. The richness of Desmodesmus sp. in OPR 3 was 12\% higher compared to OPR 1 (Fig. 2). Similarly, in the case of two full-scale wastewater high rate 
530 algal ponds (HRAPs) (NHRAPs and SHRAPs) operated over a 23 month cultivation period from 531 spring 2015 to winter 2016 in New Zealand, Desmodesmus sp., Coelastrum sp., Micractinium sp., 532 Microcystis sp., and Pediastrum sp. were the wastewater microalgal community representative of 533 the dominant species, which changed either seasonally (e.g., with retention time and loading rates) 534 or with species manipulation conditions (e.g., microalgal recycling) (Sutherland, Turnbull \& 535 Craggs, 2017; Lutzu \& Dunford, 2018). Micractinium pusillum dominated the microalgal 536 community for an 18 month cultivation period in the two HRAP systems (Sutherland, Turnbull \& 537 Craggs, 2017), while Desmodesmus sp. dominated the microalgal community for a 9 month 538 cultivation period despite changes in multiple environmental variables in the two OPR systems in 539 our study. Cho et al. (2015) performed mass cultivation with untreated municipal wastewater in 540 an HRAP for 1 year (2013-2014) in Korea. Observation of the microalgal diversity in semi541 continuous mode showed that the dominant microalgal genera in all four seasons were 542 Scenedesmus, Microcystis, and Chlorella. In contrast to our results, Scenedesmus sp. persisted in 543 Cho et al.'s (2015) culture system in all four seasons, but the three strains were not co-dominant..

544 To identify the most promising species that can be used as biodiesel feedstock for a large-scale 545 cultivation system in China. Xia et al. (2014) cultivated Desmodesmus sp. and Scenedesmus sp. 546 under outdoor conditions. In waste water treatment coupled with an HRAP, the Scenedesmus sp. 547 population, which was the dominant strain in summer (initial stages of cultivation), decreased 548 significantly and Microcystis sp. became the dominant species, although it was absent in the 549 preceding months. In spring and summer, Chlorella was the dominant genus (Cho et al., 2015). 550 The change in dominance from one genus to another was drastic and rapid, typically within 7-10 551 days (Fig. 2). The turnover rate of dominant species in natural systems may be equally fast when 552 the steady-state phase beaks down because of significant shifts in environmental changes, although 553 the low sampling frequency of many studies has made this difficult to quantify (Sutherland, 554 Turnbull \& Craggs, 2017). In the HRAP-dependent wastewater treatment process, dynamics of the 555 Scenedesmus population are highly correlated with temperature, while those of the Chlorella 556 population are highly correlated with the effluent's organic content (Cho et al., 2015). Therefore, 557 monitoring the rapid turnover of the dominant species, as shown in our study, might make it 558 challenging to maintain a desirable species at the full-scale.

559 Microalgal diversity and biomass are likely affected by different parameters, such as 560 environmental factors (e.g., temperature) and to biological and physiochemical parameters (e.g., 
561 influent microbial diversity and organic carbon, nitrates, $\mathrm{pH}$, dissolved oxygen, and conductivity

562 levels) (Zongo et al., 2019). However, the most significant factor affecting species abundance is 563 temperature. Variations in the local environment (i.e., in the temperature of the immediate 564 surroundings of a community) are crucial, not only for the ecosystem process rate, but also for 565 species assembly persistence and the direct relationship between biodiversity and ecosystem 566 functioning.

567 In the OPRs 1 and 3 systems, we found no differences in biomass productivity (mean: 8.6$5689.9 \mathrm{~g} \cdot \mathrm{m}^{-2} \cdot \mathrm{d}^{-1}$ ) and nutrient consumption rates of TN and TP (Figs. 1C and 1F). Accordingly, in 569 microalgal communities in the two full-scale wastewater HRAPs, $\sim 33$ microalgal species were 570 found but species abundance was low and not related to either productivity or nutrient removal 571 efficiency (Sutherland, Turnbull \& Craggs, 2017). As shown in our study, both nutrient removal 572 and biomass production did not differ between the two HRAPs when the dominant species was 573 the same or different between the two ponds (Sutherland, Turnbull \& Craggs, 2017). These 574 findings indicate that compared to individual species, microalgal communities are more critical 575 for OPR performance. In addition, microalgae mass cultivation for the producing biomass and 576 associated valuable compounds have gained increasing interest not only within the scientific 577 community but also at the industrial level.

578 In our study, we identified $\sim 26$ cyanobacteria species (Figs. S11 and S12), of which 579 Cyanobium gracile frequently appeared in both OPRs 1 and 3 in spring and summer, while 580 Foliisarcina bertiogensis, Spirulina major, Cyanobacterium aponinum, and Microcystis 581 aeruginosa bloomed in the fall. However, their populations were higher in OPR 1 compared to 582 OPR 3. Synechococcus elongatus and Calothrix desertica were identified only in OPR 3 in the fall 583 (Fig. S12). In the two full-scale wastewater HRAPs, identified cyanobacteria, such as 584 Dolichospermum circinale, Merismopedia tenuissima, M. aeruginosa, Microcystis flosaquae, 585 Oscillatoria sp., and Planktothrix isothrix, with the dominant species being M. aeruginosa 586 (Sutherland, Turnbull \& Craggs, 2017). The high richness of M. aeruginosa for a short duration 587 resulted in a change in the dominant species (Sutherland, Turnbull \& Craggs, 2017). In addition 588 to the microalgal community, nutrient concentrations of nitrogen and phosphorus and organic 589 carbon loads affect cyanobacteria dominance (Cho et al., 2015).

$590 \quad$ Under harsh conditions, Desmodesmus sp. produces a higher amount starch grains, oil bodies, 591 and cell wall polysaccharides and increases its symbiotic interactions with taxonomically distant 
592 invertebrates (e.g., hydroids, sponges, and polychaetes) (Baulina et al., 2016). These symbiotic 593 relationships include all possible interactions known in nature, such as mutualism, commensalism, 594 and parasitism (McKay, Gibbs, \& Vaughn, 1991). Cyanobacteria can also have symbiotic 595 interactions with microalgae. For example, the co-culture of the Louisiana-native microalga 596 Chlorella vulgaris and the cyanobacterium Leptolyngbya sp. shows commensalism to produce 597 lipids for biodiesel production (Subashchandrabose et al., 2011). On the basic of the symbiotic 598 relationship, microalgae cyanobacteria consortia can lead to a high microalgal growth rate, 599 improved nutrient and pollutant uptake, and production of metabolites with high biotechnological 600 application potential (Silaban et al., 2014). The exact metabolic mechanisms underlying such 601 interactions are unclear. However, the benefits of this growth strategy can potentially be exploited 602 in different biotechnology fields, such as biofuel production, especially if the microalgal species 603 involved possesses a high lipid contents (Lutzu \& Dunford, 2018).

604

\section{Characteristics of microalgal biomass, and fatty acids in mass cultivation}

606 The microalgal community is a more important determinant of freshwater systems and microalgal 607 biomass production in OPRs 1 and 3 compared to one individual species. The mean weight 608 percentage CHNSO values were 43.22, 6.23, 6.23, 0.46, and 30.31, respectively, in OPR 1 and $60941.50,5.86,5.62,0.41$, and 26.77, respectively, in OPR 3. The mean weight percentage CHNSO 610 values of Hapalosiphon sp. biomass are 47.94, 7.44, 6.45, 0.58, and 37.58, respectively, while 611 those of Botryococcus braunii biomass are 77.04, 12.40, 1.23, 0.18, and 9.86, respectively (Liu et 612 al., 2012). In our study, the CVs were higher in summer and the fall compared to spring and were 613 higher in OPR 1 compared to OPR 3 (Table 1). The mean CVs of OPR 1 and 3 were 19.5 and 18.5 $614 \mathrm{MJ} \cdot \mathrm{kg}^{-1}$, respectively, which are higher compared to the land plant biomass $\left(18.4 \mathrm{MJ} \cdot \mathrm{kg}^{-1}\right)(\mathrm{Ross}$ 615 et al., 2008). In general, microalgae grown under normal conditions have a CV of $18-21 \mathrm{MJ} \cdot \mathrm{kg}^{-1}$ 616 (Scragg et al., 2002). The CV of Hapalosiphon sp. is $14.75 \mathrm{MJ} \cdot \mathrm{kg}^{-1}$, similar to that of sewage 617 sludge or lignocellulose biomass (19-25 MJ $\left.\mathrm{kg}^{-1}\right)$, while the $\mathrm{CV}$ of $B$. braunii is as high as 35.58 $618 \mathrm{MJ} \cdot \mathrm{kg}^{-1}$ because of total carbon and hydrogen contents of $89.4 \%$ in the microalgal biomass, similar 619 to that of crude oil (Liu et al., 2012). Considering a high carbon and hydrogen content an advantage 620 for feedback in biofuel production, our results showed that the microalgal biomasses in OPRs 1 621 and 3 were feasible for biodiesel production, although the produced values were lower compared 622 to B. braunii. 
623 The major fatty acids of the microalgal biomasses in OPRs 1 and 3 were C16:0 (24.5\% and 24.2\%, 624 respectively), C16:1 (15.4\% and 9.7\%, respectively), C16:4 (6.0\% and 7.6\%, respectively), C18:1 625 (16.9\% and 21.9\%, respectively), C18:2 (6.1\% and 5.8\%, respectively), and C18:3 (14.1\% and 626 17.9\%, respectively) (Fig. 4). The fatty acids produced by microalgae are C16:0, C18:0, C18:1, 627 C18:2, and C18:3 (Huang et al., 2015), of which UFAs (C18:1 and C18:2) are important 628 components of high-quality biodiesel (Bouaid, Martinez \& Aracil, 2007). In our study, mean $629 \mathrm{C} 16: 0, \mathrm{C} 18: 1$, and $\mathrm{C} 18: 3$ content of the biodiesel was $24.5 \%, 17.0 \%$, and $14.5 \%$, respectively, in 630 OPR 1 (56.0\% in total) and $24.2 \%, 22.0 \%$, and $17.9 \%$, respectively, in OPR $3(64.1 \%$ in total) 631 (Fig. 4). Especially, C18:1 is an important indicator of biodiesel quality and provides great stability 632 (Ho et al., 2014). The total UFA concentration in the biodiesels derived from OPRs 1 and 3 was $63365.1 \%$ and $67.2 \%$, respectively, which was approximately two times greater compared to SFAs 634 (34.9\% and 32.8\%, respectively). The low PUFA content and high SFA and MUFA content are 635 among the most important indicators of biodiesel quality (Piligaev et al., 2018). The fatty acid 636 profiles of microalgal oils generally affect the qualities of the biodiesel produced. High SFA and 637 MUFA contents lead to high oxidative and thermal stabilities, resulting in a slower deterioration 638 rate of lipid characteristics (Mostafa \& El-Gendy, 2017).

639 In our study, we found high levels of fatty acids with a high degree of SFAs, such as C16:0. 640 In addition, MUFAs C16:1 and C18:1 were abundant in OPRs 1 and 3 (Fig. 4). According to 641 biodiesel standard EN 14214, the percentages of linolenic acid (C18:3) and PUFAs (P4 double 642 bond) should not be greater than $12 \%$ and 1\%, respectively (Mandotra et al., 2014). The fatty acid 643 profiles of microalgal biomasses in OPRs 1 and 3 had a high linolenic acid content of $14.2 \%$ and $64418.0 \%$, respectively. Assessment of the amount of FAMEs with $\geq 4$ double bonds for microalgal 645 crude oil extract has shown that the microalgal strain does not produce, FAMEs and therefore 646 represents a good biodiesel source (Mandotra et al., 2014). Microalgal fatty acid profiling of 647 biodiesel obtained from Desmodesmus sp. I-AU1 contains a total SFA methyl ester content of 648 31.0\%, while the total MUFA C18:1 content is 25.6\% (Arguelles et al., 2018). The SFA and 649 MUFA percentage composition of the microalga was $56.7 \%$, which is high relative to related 650 studies (Arguelles et al., 2018). The fatty acid content of microalgal biomasses in OPRs 1 and 3 651 mainly comprised SFAs and MUFAs (67.3\% and 64.8\%, respectively), which are suitable for 652 biodiesel production. 
654 Properties of microalgal biomass-based biodiesel quality parameters in mass cultivation

655 The fatty acid profile of microalgal oils generally affects biodiesel quality (Nascimento et al., 656 2013). The biodiesels derived from OPRs 1 and 3 had a low density $\left(0.87 \mathrm{~g} \cdot \mathrm{cm}^{-3}\right)$ and low 657 kinematic viscosity $\left(3.95 \mathrm{~mm}^{2} \cdot \mathrm{s}^{-1}\right)$. In addition, values of the other parameters were as follows: $658 \mathrm{CN}, 56.27$ and 52.97, respectively; oxidation stability, 13.02 and $11.66 \mathrm{~h}$, respectively; CFPP, $6593.8^{\circ} \mathrm{C}$ and $-3.0^{\circ} \mathrm{C}$, respectively; and $\mathrm{IV}, 85.83 \mathrm{~g} \mathrm{I}_{2} \cdot(100 \mathrm{~g})^{-1}$ fat and $97.16 \mathrm{~g} \mathrm{I}_{2} \cdot(100 \mathrm{~g})^{-1}$ fat, 660 respectively. The mean SV, DU, and LCSF were 203.60, 62.75 wt\%, and $4.03 \mathrm{wt} \%$, respectively, 661 in OPR 1 and 201.83, $69.37 \mathrm{wt} \%$, and $4.31 \mathrm{wt} \%$, respectively, in OPR 3 (Table 2). The carbon 662 chain lengths of both SFAs and UFAs in crude oil extracts generally affect biodiesel properties, 663 such as CN, oxidative stability, and cold-flow properties (Samorì et al., 2013). Generally, crude 664 oil extracts with a high proportion of SFAs and MUFAs are preferred for biodiesel production 665 because these fatty acids increase the energy yield and oxidative stability of biodiesel. On the one 666 hand, oils containing MUFAs are prone to solidification at low temperature; on the other hand, 667 oils rich in PUFAs have good cold-flow properties but are vulnerable to oxidation. This has an 668 adverse effect on fuel conservation and combustion (Arguelles et al., 2018). The total mean 669 percentages of SFAs and MUFAs and of SFAs and PUFAs for the total biomass were $67.3 \%$ and $67064.7 \%$, respectively, and 67.6\% and 68.4\%, respectively (Fig. 4). With regard to biodiesel quality, 671 microalgal biomasses in OPRs 1 and 3 showed good fuel viscosity, equal or lower density, higher $672 \mathrm{CN}$ and oxidation stability, and good performances at low temperature. Overall, our results 673 indicate that biodiesel produced from the oil Desmodesmus sp. grown in open ponds (OPR 1 or 3 ) 674 will have low emissions, good combustion, good flow properties at low temperatures, and 675 excellent oxidation stability.

676

\section{Application of microalgae as biological enhancers}

678 The bioenhancing ability of microalgae is based on the phenotype. The first assessment showed 679 that the group subjected to the microalgal biomass (1-4 and 1-5), cleared solution (1-3), or spray 680 (1-6) of OPR 1 has improved growth compared to control groups (1-1 and 1-2), while groups 681 treated with the cleared solution (3-3) or spray (3-6) of OPR 3 display an improved phenotype 682 compared to other groups (Figs. 6A-E and S13). Consistent with our results, microalgae have been 683 considered a potential biofertilizer to replace mainstream synthetic fertilizers in order to enhance

684 the biological and chemical properties of soil, positively affecting plant characteristics and 
685 increasing yields (Ronga et al., 2019). For example, inoculation of C. vulgaris and S. dimorphus 686 increases rice yields by improving nitrogen fixation (Garcia-Gonzalez \& Sommerfeld, 2016). The 687 culture solution, cellular extracts, and dry biomass of Acutodesmus dimorphus enhances seed 688 germination, plant growth, and floral production in Roma tomato (Jochum, Moncayo \& Jo, 2018). 689 Therefore, the microalgal biomass and culture solutions of OPRs 1 and 3 improved the agronomic 690 traits of soybean plants and can be introduced as biological enhancers, such as soybean spray and 691 biofertilizer.

692

693 Conclusions

694 This study investigated the species diversity of the microalgal community during mass cultivation. 695 Desmodesmus sp. was found to be the dominant microalgal species throughout the evaluation 696 period. The microalgal biomasses produced from OPRs 1 and 3 are rich in SFAs (C16:0), MUFAs 697 (C16:1 and C18:1), and PUFAs (C16:4 and C18:3). The biodiesel derived from the microalgal 698 biomasses showed good fuel viscosity, equal or lower density, higher CN and oxidation stability, 699 and good performance at low temperature, meeting the major biodiesel standards. The microalgal 700 biomass and culture solution of OPRs 1 or 3 improved the environmental adaptation of soybean 701 plants. Therefore, OPR-grown Desmodesmus sp. is a potential alternative feedstock for producing 702 excellent-quality biodiesel and biofertilizer. In addition, the understanding of microalgal diversity 703 can help sustain a dominant genus in OPR systems, maximizing overall efficiency. Following a 704 decrease in water temperature, eukaryotic diversity is highest in summer compared to spring and 705 the fall. In addition, quantitative analysis of the phytoplankton community, which is important for 706 ecological studies, has problems of low accuracy of species identification (which heavily depends 707 on personnel experience) and low efficiency and is also time consuming. As an alternative to

708

709 710

\section{Acknowledgments}

712 This study was supported by a grant from the National Research Foundation of Korea (NRF713 2017R1A2B4002016). This work was supported by a grant from the Next-Generation BioGreen 71421 Program (No. PJ013240), Rural Development Administration, Korea.

715 


\section{References}

717 Abou-Shanab RAI, Hwang JH, Cho Y, Min B, Jeon BH. 2011. Characterization of microalgal 718 species isolated from fresh water bodies as a potential source for biodiesel production.

719 Applied Energy 88:3300-3306. DOI: 10.1016/j.apenergy.2011.01.060.

720 Alishah Aratboni H, Rafiei N, Garcia-Granados R, Alemzadeh A, Morones-Ramírez JR. 2019.

721 Biomass and lipid induction strategies in microalgae for biofuel production and other 722 applications. Microbial Cell Factories 18:1-17. DOI: 10.1186/s12934-019-1228-4.

723 Amaral-Zettler LA, McCliment EA, Ducklow HW, Huse SM. 2009. A method for studying 724 protistan diversity using massively parallel sequencing of $\mathrm{V} 9$ hypervariable regions of 725 small-subunit ribosomal RNA Genes. PLoS ONE 4:1-9. DOI:

$726 \quad$ 10.1371/journal.pone.0006372.

727 Arguelles ED, Laurena AC, Monsalud RG, Martinez-Goss MR. 2018. Fatty acid profile and fuel-

728

729

730

731

732

733

734

735

736

737

738

739

740

741

742

743

744

745 derived physico-chemical properties of biodiesel obtained from an indigenous green microalga, Desmodesmus sp. (I-AU1), as potential source of renewable lipid and high quality biodiesel. Journal of Applied Phycology 30:411-419. DOI: 10.1007/s10811-0171264-6.

Awaluddin SA, Thiruvenkadam S, Izhar S, Hiroyuki Y, Danquah MK, Harun R. 2016. Subcritical Water Technology for Enhanced Extraction of Biochemical Compounds from Chlorella vulgaris. BioMed Research International 2016. DOI: 10.1155/2016/5816974.

Baulina O, Gorelova O, Solovchenko A, Chivkunova O, Semenova L, Selyakh I, Scherbakov P, Burakova O, Lobakova E. 2016. Diversity of the nitrogen starvation responses in subarctic Desmodesmus sp. (Chlorophyceae) strains isolated from symbioses with invertebrates. FEMS Microbiology Ecology 92:1-12. DOI: 10.1093/femsec/fiw031.

Bell TAS, Prithiviraj B, Wahlen BD, Fields MW, Peyton BM. 2016. A lipid-accumulating alga maintains growth in outdoor, alkaliphilic raceway pond with mixed microbial communities. Frontiers in Microbiology 6:1-12. DOI: 10.3389/fmicb.2015.01480.

Bouaid A, Martinez M, Aracil J. 2007. Long storage stability of biodiesel from vegetable and used frying oils. Fuel 86:2596-2602. DOI: 10.1016/j.fuel.2007.02.014.

Bradley, Ian M, Pinto, Ameet J, Guest JS. 2016. Design and Evaluation of Illumina MiseqCompatible, 18S rRNA Gene-Specific Primers for Improved Characterization of Mixed 
746

747

748

749

750

751

752

753

754

755

756

757

758

759

760

761

762

763

764

765

766

767

768

769

770

771

772

773

774

775

Phototrophic Communities. Applied and Environmental Microbiology 82:5878-5891. DOI: 10.1128/AEM.01630-16.Editor.

Breuer G, Evers WAC, de Vree JH, Kleinegris DMM, Martens DE, Wijffels RH, Lamers PP. 2013. Analysis of Fatty Acid Content and Composition in Microalgae. Journal of Visualized Experiments 5:1-9. DOI: 10.3791/50628.

Caporaso JG, Kuczynski J, Stombaugh J, Bittinger K, Bushman FD, Costello EK, Fierer N, Peña AG, Goodrich JK, Gordon JI, Huttley GA, Kelley ST, Knights D, Koenig JE, Ley RE, Lozupone CA, Mcdonald D, Muegge BD, Pirrung M, Reeder J, Sevinsky JR, Turnbaugh PJ, Walters WA, Widmann J, Yatsunenko T, Zaneveld J, Knight R. 2010. QIIME allows analysis of high- throughput community sequencing data Intensity. Nature Publishing Group 7:335-336. DOI: 10.1038/nmeth0510-335.

Caporaso JG, Lauber CL, Walters WA, Berg-Lyons D, Huntley J, Fierer N, Owens SM, Betley J, Fraser L, Bauer M, Gormley N, Gilbert JA, Smith G, Knight R. 2012. Ultra-highthroughput microbial community analysis on the Illumina HiSeq and MiSeq platforms. ISME Journal 6:1621-1624. DOI: 10.1038/ismej.2012.8.

Cheng J, Zhu Y, Zhang Z, Yang W. 2019. Modification and improvement of microalgae strains for strengthening CO2 fixation from coal-fired flue gas in power plants. Bioresource Technology 291. DOI: 10.1016/j.biortech.2019.121850.

Cheung SL, Allen DG, Short SM. 2020. Specific quantification of Scenedesmus obliquus and Chlorella vulgaris in mixed-species algal biofilms. Bioresource Technology 295. DOI: 10.1016/j.biortech.2019.122251.

Chisti Y. 2013. Constraints to commercialization of algal fuels. Journal of Biotechnology 167:201-214. DOI: 10.1016/j.jbiotec.2013.07.020.

Cho DH, Ramanan R, Heo J, Kang Z, Kim BH, Ahn CY, Oh HM, Kim HS. 2015. Organic carbon, influent microbial diversity and temperature strongly influence algal diversity and biomass in raceway ponds treating raw municipal wastewater. Bioresource Technology 191:481-487. DOI: 10.1016/j.biortech.2015.02.013.

Dahlin LR, Van Wychen S, Gerken HG, McGowen J, Pienkos PT, Posewitz MC, Guarnieri MT. 2018. Down-selection and outdoor evaluation of novel, halotolerant algal strains for winter cultivation. Frontiers in Plant Science 871:1-10. DOI: 10.3389/fpls.2018.01513. 
776 El-Sheekh MM, Gheda SF, El-Sayed AEKB, Abo Shady AM, El-Sheikh ME, Schagerl M. 2019.

777 Outdoor cultivation of the green microalga Chlorella vulgaris under stress conditions as a

778 feedstock for biofuel. Environmental Science and Pollution Research 26:18520-18532.

779 DOI: $10.1007 / \mathrm{s} 11356-019-05108-\mathrm{y}$.

780 Faried M, Samer M, Abdelsalam E, Yousef RS, Attia YA, Ali AS. 2017. Biodiesel production

781 from microalgae: Processes, technologies and recent advancements. Renewable and

782 Sustainable Energy Reviews 79:893-913. DOI: 10.1016/j.rser.2017.05.199.

783 Friedl A, Padouvas E, Rotter H, Varmuza K. 2005. Prediction of heating values of biomass fuel 784 from elemental composition. Analytica Chimica Acta 544:191-198. DOI:

$785 \quad$ 10.1016/j.aca.2005.01.041.

786 Garcia-Gonzalez J, Sommerfeld M. 2016. Biofertilizer and biostimulant properties of the 787 microalga Acutodesmus dimorphus. Journal of Applied Phycology 28:1051-1061. DOI:

$788 \quad 10.1007 / \mathrm{s} 10811-015-0625-2$.

789 Giacomelli GA, Roberts WJ. 1993. Greenhouse Covering Systems. HortTechnology 3:50-58.

790 DOI: $10.21273 /$ horttech.3.1.50.

791 Guo L, Sui Z, Liu Y. 2016. Quantitative analysis of dinoflagellates and diatoms community via

792 Miseq sequencing of actin gene and v9 region of 18S rDNA. Scientific Reports 6:1-9. DOI:

$793 \quad 10.1038 /$ srep34709.

794 Ho S-H, Nakanishi A, Ye X, Chang J-S, Hara K, Hasunuma T, Kondo A. 2014. Optimizing

795 biodiesel production in marine Chlamydomonas sp. JSC4 through metabolic profiling and

796 an innovative salinity-gradient strategy. Biotechnology for Biofuels 7:97. DOI:

797 10.1186/1754-6834-7-97.

798 Hong JW, Kim OH, Jo SW, Do JM, Yoon HS. 2017. Microalgal biomass productivity and 799 dominant species transition in a Korean mass cultivation system. Algal Research 26:365800 370. DOI: 10.1016/j.algal.2017.08.013.

801 Huang Y, Cheng J, Lu H, Huang R, Zhou J, Cen K. 2015. Simultaneous enhancement of 802 microalgae biomass growth and lipid accumulation under continuous aeration with $15 \%$ 803 CO2. RSC Advances 5:50851-50858. DOI: 10.1039/c5ra08401f.

804 Hugenholtz P, Pitulle C, Hershberger KL, Pace NR. 1998. Novel division level bacterial 805 diversity in a Yellowstone hot spring. Journal of Bacteriology 180:366-376. 
806 Ishaq SL, Wright A-DG. 2014. Design and Validation of Four New Primers for Next-Generation 807 Sequencing To Target the 18S rRNA Genes of Gastrointestinal Ciliate Protozoa. Applied 808 and Environmental Microbiology 80:5515-5521. DOI: 10.1128/aem.01644-14.

809 Jebali A, Acién FG, Jiménez-Ruiz N, Gómez C, Fernández-Sevilla JM, Mhiri N, Karray F, 810 Sayadi S, Molina-Grima E. 2019. Evaluation of native microalgae from Tunisia using the 811 pulse-amplitude-modulation measurement of chlorophyll fluorescence and a performance 812 study in semi-continuous mode for biofuel production. Biotechnology for Biofuels 12:1-17. 813 DOI: $10.1186 / \mathrm{s} 13068-019-1461-4$.

814 Jochum M, Moncayo LP, Jo YK. 2018. Microalgal cultivation for biofertilization in rice plants 815 using a vertical semi-closed airlift photobioreactor. PLoS ONE 13:1-13. DOI: $816 \quad$ 10.1371/journal.pone.0203456.

817 Kim BH, Choi JE, Cho K, Kang Z, Ramanan R, Moon DG, Kim HS. 2018. Influence of water 818 depth on microalgal production, biomass harvest, and energy consumption in high rate algal 819 pond using municipal wastewater. Journal of Microbiology and Biotechnology 28:630-637. 820 DOI: $10.4014 /$ jmb.1801.01014.

821 Kim H, Kim H, Hwang HS, Kim W. 2017. Metagenomic analysis of the marine coastal 822 invertebrates of South Korea as assessed by Ilumina MiSeq. Animal Cells and Systems $823 \quad 21: 37-44$. DOI: 10.1080/19768354.2016.1271012.

824 Kozich JJ, Westcott SL, Baxter NT, Highlander SK, Schloss PD. 2013. Development of a Dual825 Index Sequencing Strategy and Curation Pipeline for Analyzing Amplicon Sequence Data 826 on the MiSeq Illumina Sequencing Platform. Applied and Environmental Microbiology 827 79:5112-5120. DOI: 10.1128/aem.01043-13.

828 Krohn-Molt I, Alawi M, Förstner KU, Wiegandt A, Burkhardt L, Indenbirken D, Thieß M, 829 Grundhoff A, Kehr J, Tholey A, Streit WR. 2017. Insights into Microalga and bacteria 830 interactions of selected phycosphere biofilms using metagenomic, transcriptomic, and 831 proteomic approaches. Frontiers in Microbiology 8:1-14. DOI: 10.3389/fmicb.2017.01941. 832 Liu YQ, Lim LRX, Wang J, Yan R, Mahakhant A. 2012. Investigation on pyrolysis of 833 microalgae botryococcus braunii and Hapalosiphon sp. Industrial and Engineering 834 Chemistry Research 51:10320-10326. DOI: 10.1021/ie202799e. 
835 Lutzu GA, Dunford NT. 2018. Interactions of microalgae and other microorganisms for 836 enhanced production of high-value compounds. Frontiers in Bioscience - Landmark $83723: 1487-1504$. DOI: $10.2741 / 4656$.

838 Mandotra SK, Kumar P, Suseela MR, Ramteke PW. 2014. Fresh water green microalga 839 Scenedesmus abundans: A potential feedstock for high quality biodiesel production. 840 Bioresource Technology 156:42-47. DOI: 10.1016/j.biortech.2013.12.127.

841 McKay RML, Gibbs SP, Vaughn KC. 1991. RuBisCo activase is present in the pyrenoid of 842 green algae. Protoplasma 162:38-45. DOI: 10.1007/BF01403899.

843 Mishra SK, Suh WI, Farooq W, Moon M, Shrivastav A, Park MS, Yang JW. 2014. Rapid 844 quantification of microalgal lipids in aqueous medium by a simple colorimetric method. 845 Bioresource Technology 155:330-333. DOI: 10.1016/j.biortech.2013.12.077.

846 Mostafa SSM, El-Gendy NS. 2017. Evaluation of fuel properties for microalgae Spirulina 847 platensis bio-diesel and its blends with Egyptian petro-diesel. Arabian Journal of Chemistry 848 10:S2040-S2050. DOI: 10.1016/j.arabjc.2013.07.034.

849 de Muinck EJ, Trosvik P, Gilfillan GD, Hov JR, Sundaram AYM. 2017. A novel ultra high850 throughput 16S rRNA gene amplicon sequencing library preparation method for the 851 Illumina HiSeq platform. Microbiome 5:68. DOI: 10.1186/s40168-017-0279-1.

852 Nascimento IA, Marques SSI, Cabanelas ITD, Pereira SA, Druzian JI, de Souza CO, Vich DV, 853 de Carvalho GC, Nascimento MA. 2013. Screening Microalgae Strains for Biodiesel 854 Production: Lipid Productivity and Estimation of Fuel Quality Based on Fatty Acids 855 Profiles as Selective Criteria. Bioenergy Research 6:1-13. DOI: 10.1007/s12155-012-92228562.

857 Ng IS, Tan SI, Kao PH, Chang YK, Chang JS. 2017. Recent Developments on Genetic 858 Engineering of Microalgae for Biofuels and Bio-Based Chemicals. Biotechnology Journal 859 12:1-13. DOI: 10.1002/biot.201600644.

860 Ondov BD, Bergman NH, Phillippy AM. 2011. Interactive metagenomic visualization in a Web 861 browser. BMC Bioinformatics 12. DOI: 10.1186/1471-2105-12-385.

862 Park JBK, Craggs RJ, Shilton AN. 2013. Enhancing biomass energy yield from pilot-scale high 863 rate algal ponds with recycling. Water Research 47:4422-4432. DOI:

$864 \quad$ 10.1016/j.watres.2013.04.001. 
865 Patel A, Matsakas L, Rova U, Christakopoulos P. 2019. A perspective on biotechnological 866 applications of thermophilic microalgae and cyanobacteria. Bioresource Technology 867 278:424-434. DOI: 10.1016/j.biortech.2019.01.063.

868 Piligaev A V., Sorokina KN, Shashkov M V., Parmon VN. 2018. Screening and comparative 869 metabolic profiling of high lipid content microalgae strains for application in wastewater 870 treatment. Bioresource Technology 250:538-547. DOI: 10.1016/j.biortech.2017.11.063.

871 Posadas E, Morales M del M, Gomez C, Acién FG, Muñoz R. 2015. Influence of pH and CO2 872 source on the performance of microalgae-based secondary domestic wastewater treatment in 873 outdoors pilot raceways. Chemical Engineering Journal 265:239-248. DOI:

874

875 Ramos MJ, Fernández CM, Casas A, Rodríguez L, Pérez Á. 2009. Influence of fatty acid 876 composition of raw materials on biodiesel properties. Bioresource Technology 100:261877 268. DOI: $10.1016 /$ j.biortech.2008.06.039.

878 Ranganathan P, Amal JC, Savithri S, Haridas A. 2017. Experimental and modelling of 879 Arthrospira platensis cultivation in open raceway ponds. Bioresource Technology 242:197880 205. DOI: $10.1016 /$ j.biortech.2017.03.150.

881 Ren H, Tuo J, Addy MM, Zhang R, Lu Q, Anderson E, Chen P, Ruan R. 2017. Cultivation of 882 Chlorella vulgaris in a pilot-scale photobioreactor using real centrate wastewater with waste 883 glycerol for improving microalgae biomass production and wastewater nutrients removal. 884 Bioresource Technology 245:1130-1138. DOI: 10.1016/j.biortech.2017.09.040.

885 Roccuzzo S, Beckerman AP, Pandhal J. 2016. The use of natural infochemicals for sustainable 886 and efficient harvesting of the microalgae Scenedesmus spp. for biotechnology: insights 887 from a meta-analysis. Biotechnology Letters 38:1983-1990. DOI: 10.1007/s10529-016$888 \quad 2192-2$.

889 Rodolfi L, Zittelli GC, Bassi N, Padovani G, Biondi N, Bonini G, Tredici MR. 2009. Microalgae 890 for oil: Strain selection, induction of lipid synthesis and outdoor mass cultivation in a low891 cost photobioreactor. Biotechnology and Bioengineering 102:100-112. DOI: $892 \quad$ 10.1002/bit.22033.

893 Ronga D, Biazzi E, Parati K, Carminati D, Carminati E, Tava A. 2019. Microalgal biostimulants 894 and biofertilisers in crop productions. Agronomy 9:1-22. DOI: 10.3390/agronomy9040192. 
895 Ross AB, Jones JM, Kubacki ML, Bridgeman T. 2008. Classification of macroalgae as fuel and 896 its thermochemical behaviour. Bioresource Technology 99:6494-6504. DOI:

897 10.1016/j.biortech.2007.11.036.

898

Sambles C, Moore K, Lux TM, Jones K, Littlejohn GR, Gouveia JD, Aves SJ, Studholme DJ,

899

900

901

902

903

904

905

906

907

908

909

910

911

912

913

914

915

916

917

918

919

920

921

922

923

924

\section{Lee R, Love J. 2017. Metagenomic analysis of the complex microbial consortium} associated with cultures of the oil-rich alga Botryococcus braunii. MicrobiologyOpen 6:1-9. DOI: $10.1002 / \mathrm{mbo} 3.482$.

Samorì G, Samorì C, Guerrini F, Pistocchi R. 2013. Growth and nitrogen removal capacity of Desmodesmus communis and of a natural microalgae consortium in a batch culture system in view of urban wastewater treatment: Part I. Water Research 47:791-801. DOI: 10.1016/j.watres.2012.11.006.

Scragg AH, Illman AM, Carden A, Shales SW. 2002. Growth of microalgae with increased calorific values in a tubular bioreactor. Biomass and Bioenergy 23:67-73. DOI: 10.1016/S0961-9534(02)00028-4.

Serrana JM, Miyake Y, Gamboa M, Watanabe K. 2019. Comparison of DNA metabarcoding and morphological identification for stream macroinvertebrate biodiversity assessment and monitoring. Ecological Indicators 101:963-972. DOI: 10.1016/j.ecolind.2019.02.008.

Siddiqui A, Wei Z, Boehm M, Ahmad N. 2019. Engineering microalgae through chloroplast transformation to produce high-value industrial products. Biotechnology and Applied Biochemistry:1-11. DOI: 10.1002/bab.1823.

Sijil P V., Sarada R, Chauhan VS. 2019. Enhanced accumulation of alpha-linolenic acid rich lipids in indigenous freshwater microalga Desmodesmus sp.: The effect of low-temperature on nutrient replete, UV treated and nutrient stressed cultures. Bioresource Technology 273:404-415. DOI: 10.1016/j.biortech.2018.11.028.

Silaban A, Bai R, Gutierrez-Wing MT, Negulescu II, Rusch KA. 2014. Effect of organic carbon, $\mathrm{C}: \mathrm{N}$ ratio and light on the growth and lipid productivity of microalgae/cyanobacteria coculture. Engineering in Life Sciences 14:47-56. DOI: 10.1002/elsc.201200219.

Simas-Rodrigues C, Villela HDM, Martins AP, Marques LG, Colepicolo P, Tonon AP. 2015. Microalgae for economic applications: Advantages and perspectives for bioethanol. Journal of Experimental Botany 66:4097-4108. DOI: 10.1093/jxb/erv130. 
925 Song M, Pei H, Hu W, Ma G. 2013. Evaluation of the potential of 10 microalgal strains for 926 biodiesel production. Bioresource Technology 141:245-251. DOI:

$927 \quad$ 10.1016/j.biortech.2013.02.024.

928 Subashchandrabose SR, Ramakrishnan B, Megharaj M, Venkateswarlu K, Naidu R. 2011. 929 Consortia of cyanobacteria/microalgae and bacteria: Biotechnological potential. 930 Biotechnology Advances 29:896-907. DOI: 10.1016/j.biotechadv.2011.07.009.

931 Sutherland DL, Turnbull MH, Craggs RJ. 2017. Environmental drivers that influence microalgal $932 \quad$ species in fullscale wastewater treatment high rate algal ponds. Water Research 124:504 933 512. DOI: 10.1016/j.watres.2017.08.012.

934 Xia L, Rong J, Yang H, He Q, Zhang D, Hu C. 2014. NaCl as an effective inducer for lipid 935 accumulation in freshwater microalgae Desmodesmus abundans. Bioresource Technology 936 161:402-409. DOI: 10.1016/j.biortech.2014.03.063.

937 Xie Y, Zhao X, Chen J, Yang X, Ho SH, Wang B, Chang JS, Shen Y. 2017. Enhancing cell 938 growth and lutein productivity of Desmodesmus sp. F51 by optimal utilization of inorganic 939 940

941 Young REB, Purton S. 2016. Codon reassignment to facilitate genetic engineering and 942 biocontainment in the chloroplast of Chlamydomonas reinhardtii. Plant Biotechnology 943 Journal 14:1251-1260. DOI: 10.1111/pbi.12490.

944 Znad H, Al Ketife AMD, Judd S, AlMomani F, Vuthaluru HB. 2018. Bioremediation and 945 nutrient removal from wastewater by Chlorella vulgaris. Ecological Engineering 110:1-7. 946 DOI: 10.1016/j.ecoleng.2017.10.008.

947 Zongo B, Zongo F, Thiombiano A, Boussim JI. 2019. Phytoplankton assemblages and 948 community structure in tropical temporary freshwater ponds in sub-Saharan Africa1. 949 Journal of Phycology 55:789-800. DOI: 10.1111/jpy.12843.

950 
Figure 1

Nutrient consumption, biomass levels, and lipid content in relation to cultivation parameters from April to November, 2017.

Environmental cultivation factors were monitored by measuring the $(\mathrm{A})$ water temperature and (B) pH. Black circle, OPR 1; white circle, OPR 3. (C) Nutrient consumption rate assessed by examining removal of TN and TP. Red, OPR 1 TN; light-blue, OPR 3 TN; light-red, OPR 1 TP; blue, OPR 3 TP. (D) Biomass monitored by measuring the OD at $680 \mathrm{~nm}$ for the indicated time. Light-red circle, OPR 1; light-blue circle, OPR 3. (E, F) Biomass productivity also represented DW ( $\mathrm{g} \cdot \mathrm{L}^{-1}$ and $\mathrm{g} \mathrm{DW} \mathrm{m}^{-2} \cdot$ day $\left.^{-1}\right)$. Light-red bar, OPR 1; light-blue bar, OPR 3. OPR, open pond raceway; TN, total nitrate; TP, total phosphorous; OD, optical density; DW, dry weight.

A

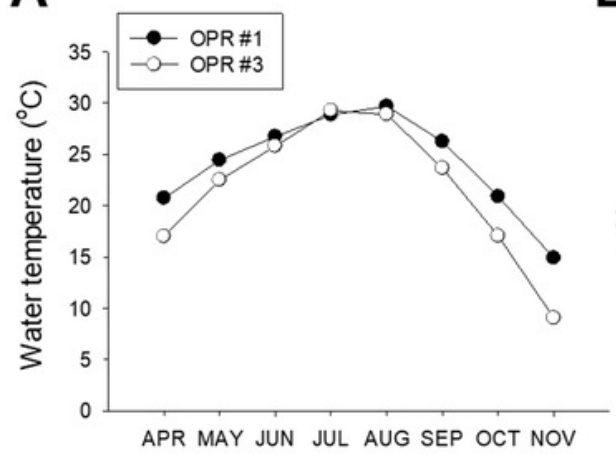

D

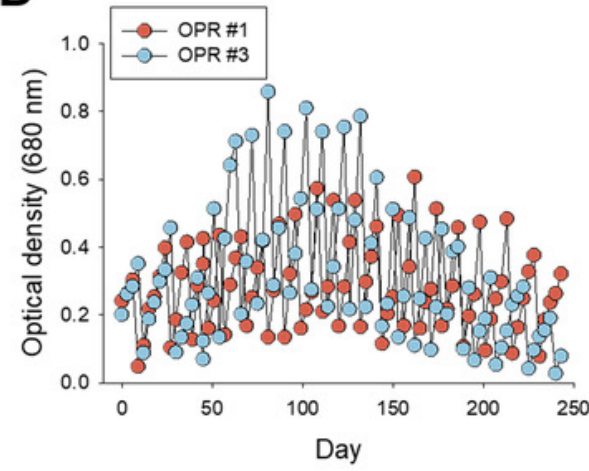

B

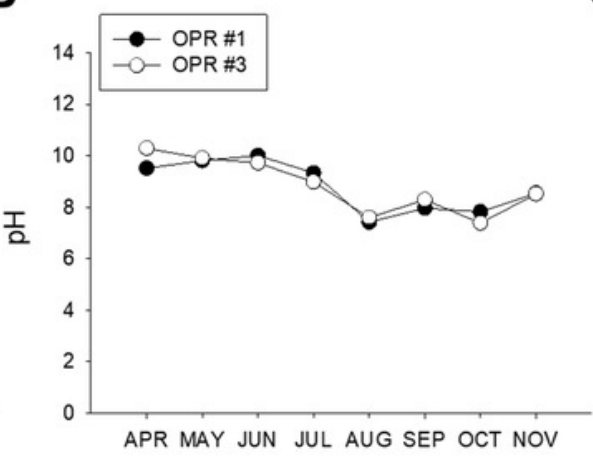

E

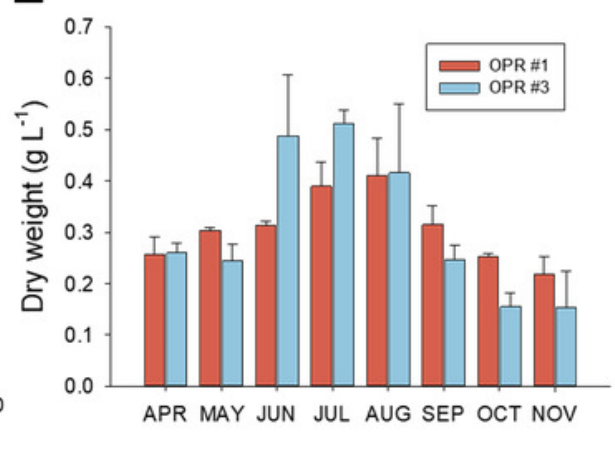

C

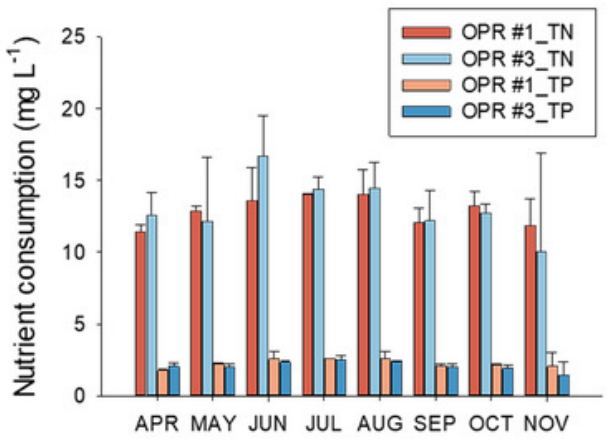

F

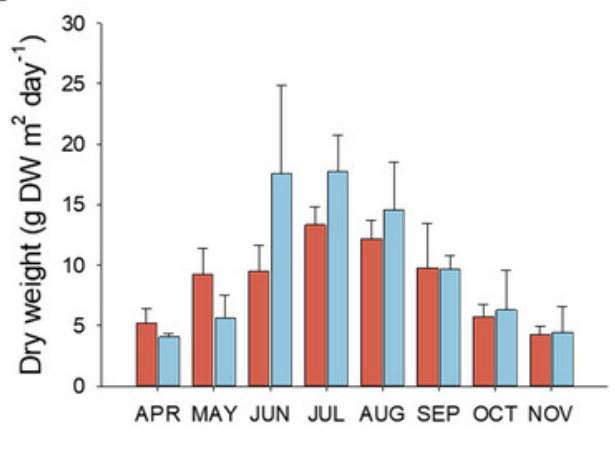




\section{Figure 2}

Fig. 2. MiSeq-based identification of the eukaryotic community, including microalgae, from April to November during mass cultivation in OPR 1 and 3.

MiSeq-based identification of the eukaryotic community, including microalgae, from April to November during mass cultivation in (A) OPR 1 and (B) OPR 3. (C) The eukaryotic community was described at the species-level, with $\sim 80$ species found in both OPRs 1 and 3, 24 in OPR 1 , and 23 in OPR 3. OPR, open pond raceway.

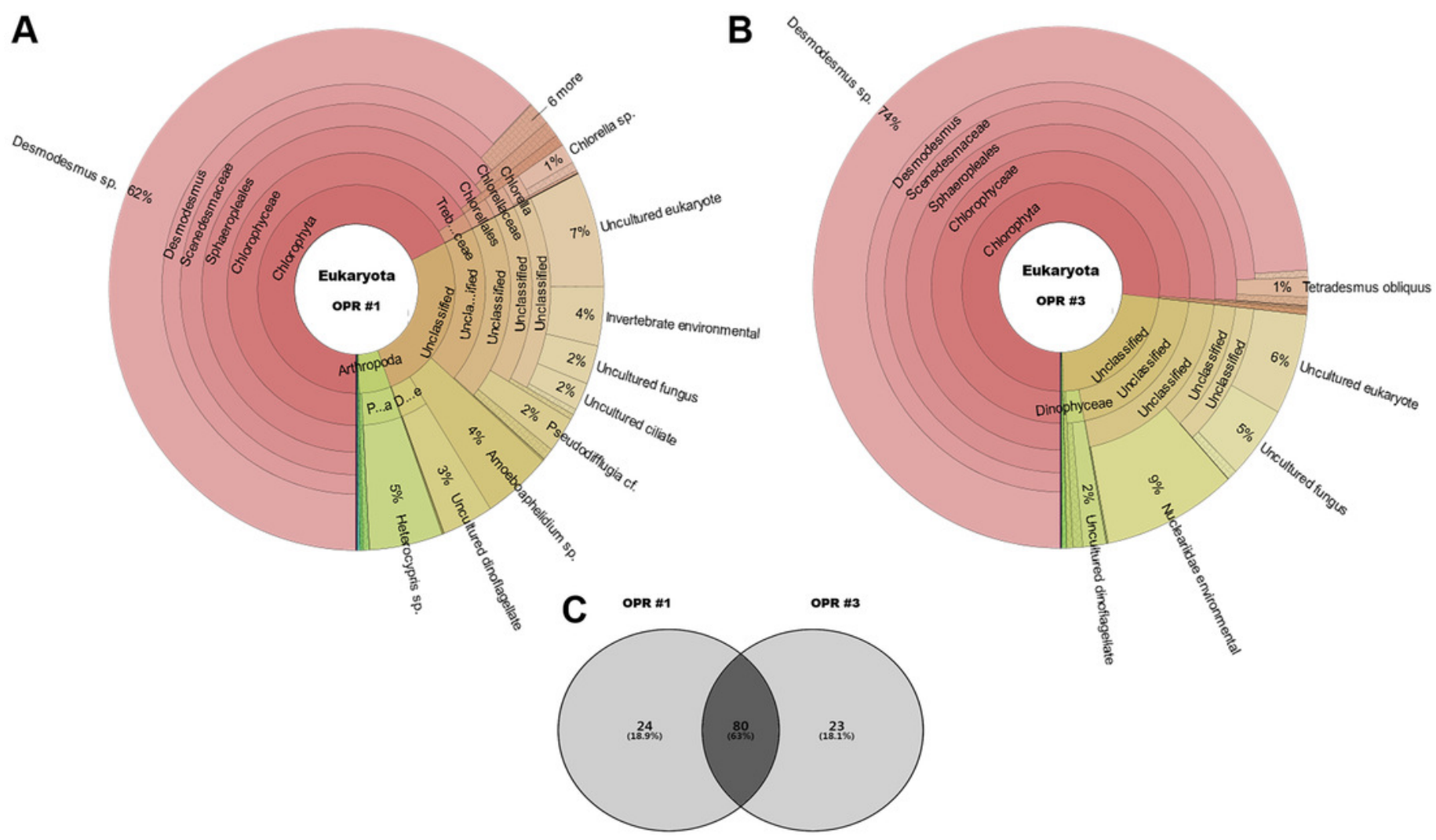




\section{Figure 3}

Fig. 3. Microalgal community from April to November during the mass cultivation period. Population abundance of OPR 1 and OPR 3 algal species.

Microalgal community from April to November 2017 during mass cultivation. Population abundance of microalgal species in (A) OPR 1 and (B) OPR 3. Wine, Desmodesmus sp.; orange, Pseudopediastrum integrum; blue, Tetradesmus obliquus; dark cyan, Chlorella sp.; magenta, Chlorella miniata; dark yellow, others. Microalgal calendar in OPRs 1 and 3 during mass cultivation. Dominant microalgal strain in ( $C-G)$ OPR 1 and (P-T) OPR 3 from April to November 2017. Microscopy-based microalgal richness in (H-O) OPR 1 and (U-BB) OPR 3 during the same period. OPR, open pond raceway .
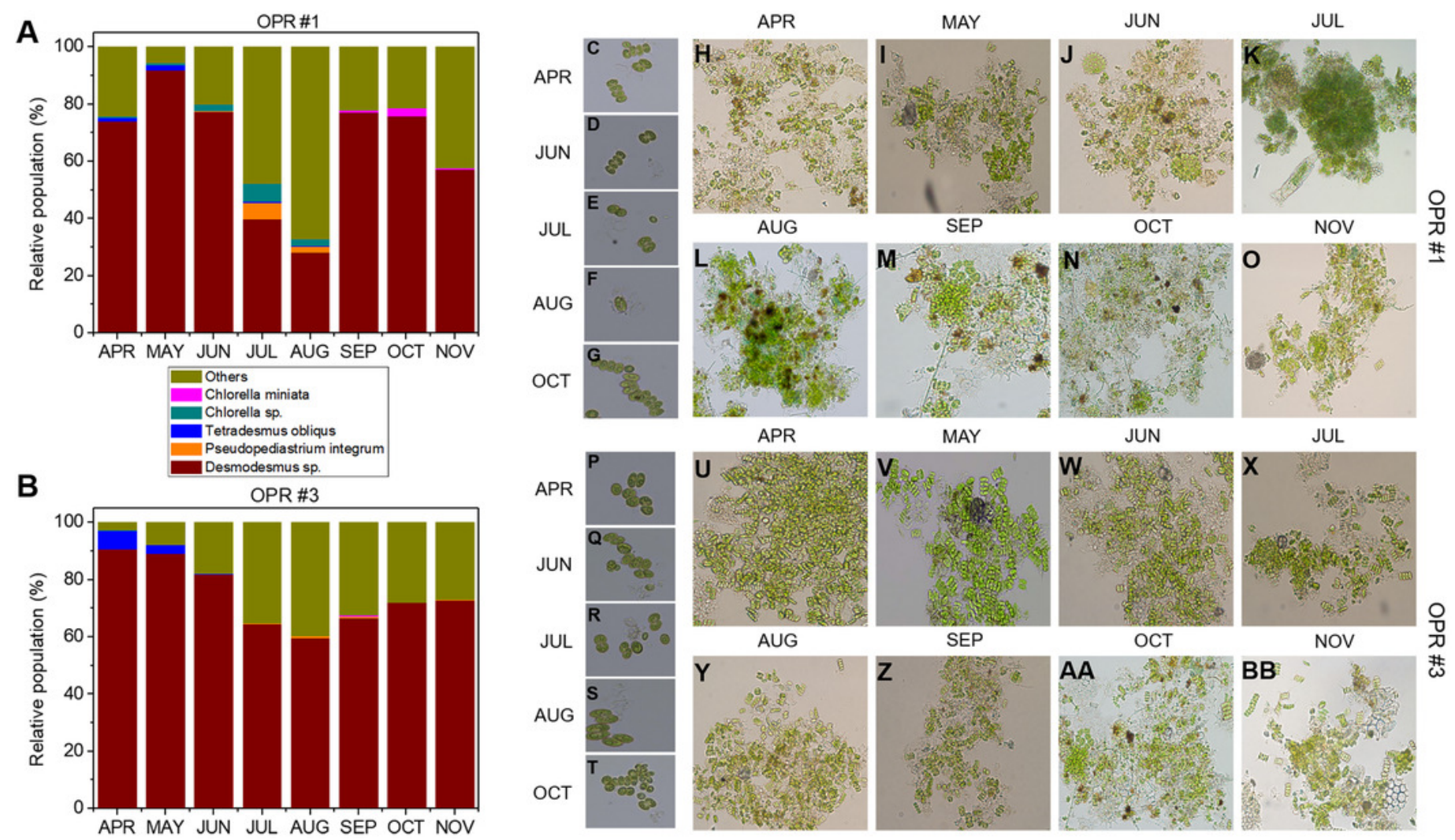


\section{Figure 4}

Fig. 4. Relative fatty acid analysis in OPR 1 and OPR 3.

Relative fatty acid analysis in (A) OPR 1 and (B) OPR 3. Fatty acid composition was set at 100\%. Wine, C14:0; red, C15:0; light-red, C16:0; apricot, C16:1; incarnadine, C16:2; white, C16:3; light sky blue, C16:4; sky blue, C18:0; light-blue, C18:1; blue, C18:2; navy, C18:3. OPR, open pond raceway.
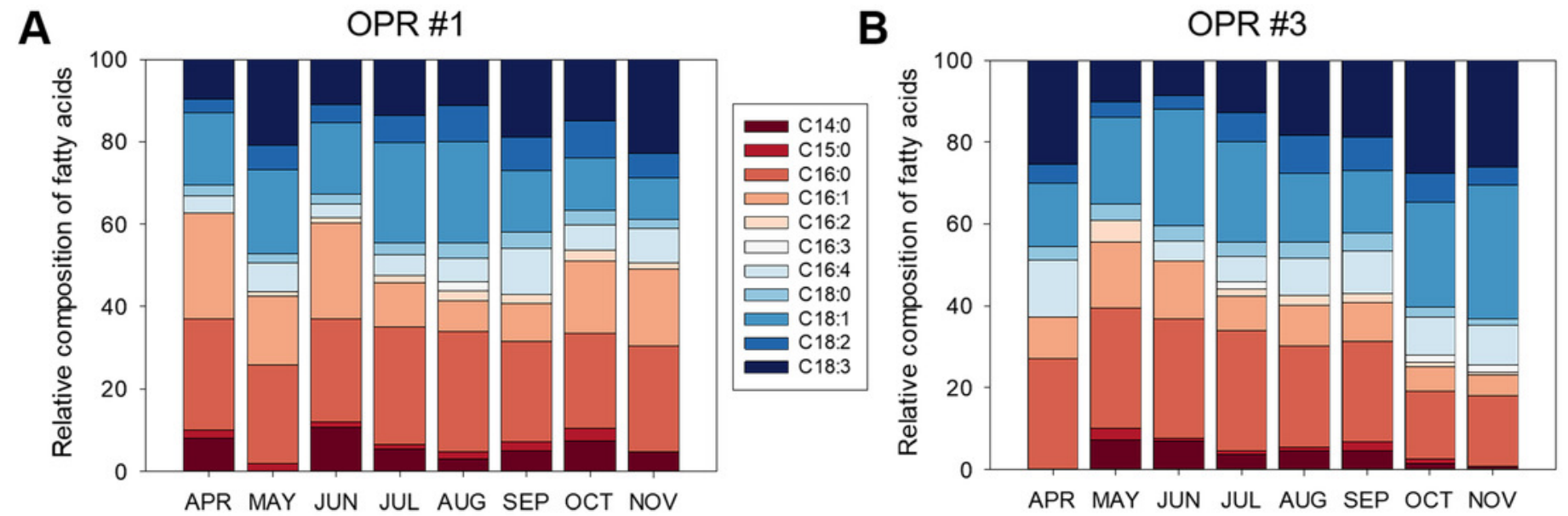


\section{Figure 5}

Fig. 5. Microalgal calendar and weather changes during mass cultivation in 2018.

Microalgal calendar and weather changes during mass cultivation in 2018. The dominant microalgal species was similar in 2017 and 2018; the presented images were taken under a microscope at 400x magnification. Microalgal calendar of (A-H) OPR 1 and (I-P) OPR 3 from April to November 2017. (Q) Changes in the mean (square), maximum (circle), and minimum (triangle) temperatures $\left({ }^{\circ} \mathrm{C}\right)$, total sunshine hours ( $\mathrm{h}$; star), and precipitation ( $\mathrm{mm}$; diamond). OPR, open pond raceway.
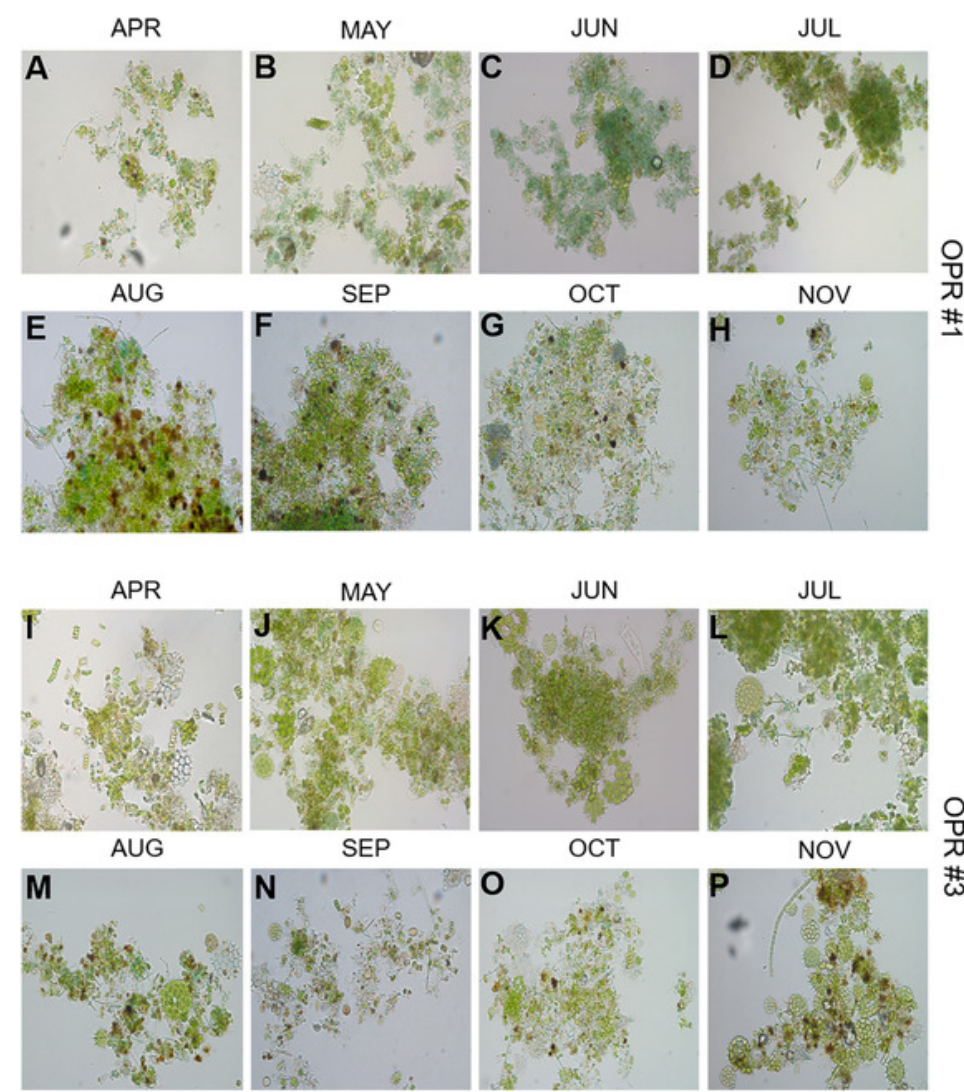

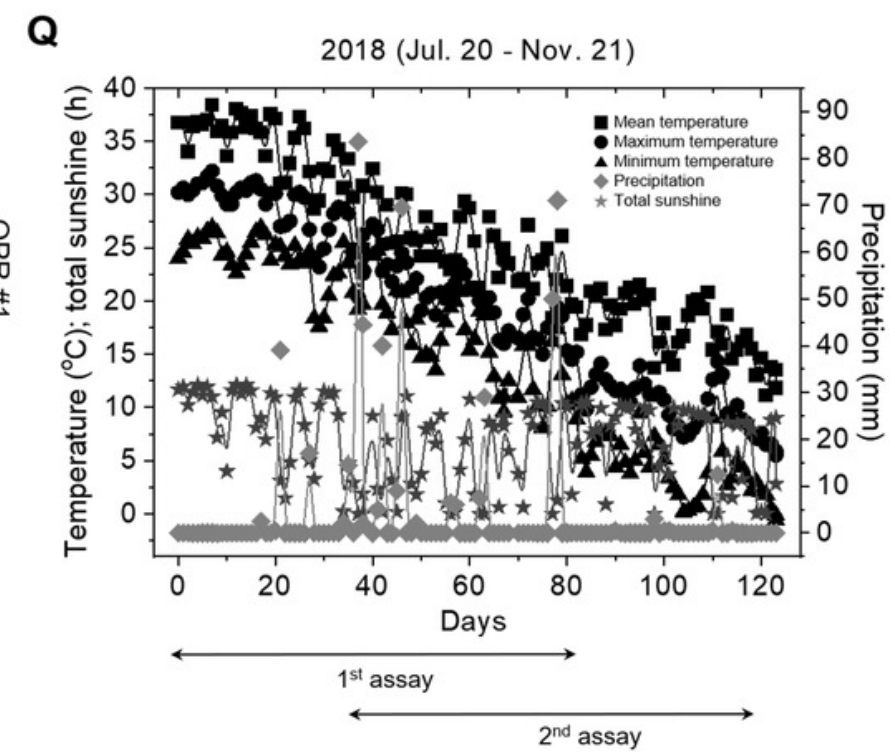




\section{Figure 6}

Fig. 6. Biofertilizer assays for soybean plants.

Biofertilizer assays for soybean plants. The first biofertilizer experiment was conducted under field conditions from July 20 to September 28, 2018. Soybean seeds were grown in potting soil. V2 seedlings were transplanted after $\sim 15$ days to $30 \mathrm{~cm}$ pots ( 15 seedlings/pot). The plants were grown for 11 weeks and hand-watered, as needed. Phenotypes in the growth stage were represented at (A) 0 , (B) 28 , (C) 56, and (D, E) 70 days after soybean seedling transplantation. The effects of a mass culture solution as a soil drench were also examined by $(F, G)$ monitoring seed development and $(H)$ weighing the pods per seedling. $a$, OPR $1 ; b$, OPR 3; 1-1 and 3-1, soybean plants supplemented with groundwater; 1-2 and 3-2, soybean plants supplemented with eco-sol medium; 1-3 and 3-3, soybean plants supplemented with the clear supernatant from OPRs 1 and 3; 1-4 and 3-4, soybean plants supplemented with microalgal biomasses from OPRs 1 and 3; 1-5 and 3-5, soybean plants supplemented with the cultured solution (supernatant plus microalgal biomasses) from OPRs 1 and 3; 1-6 and 3-6, soybean plants sprayed with the clear supernatant from OPRs 1 and 3; gray bar, OPR 1; black bar, OPR 3. OPR, open pond raceway. 

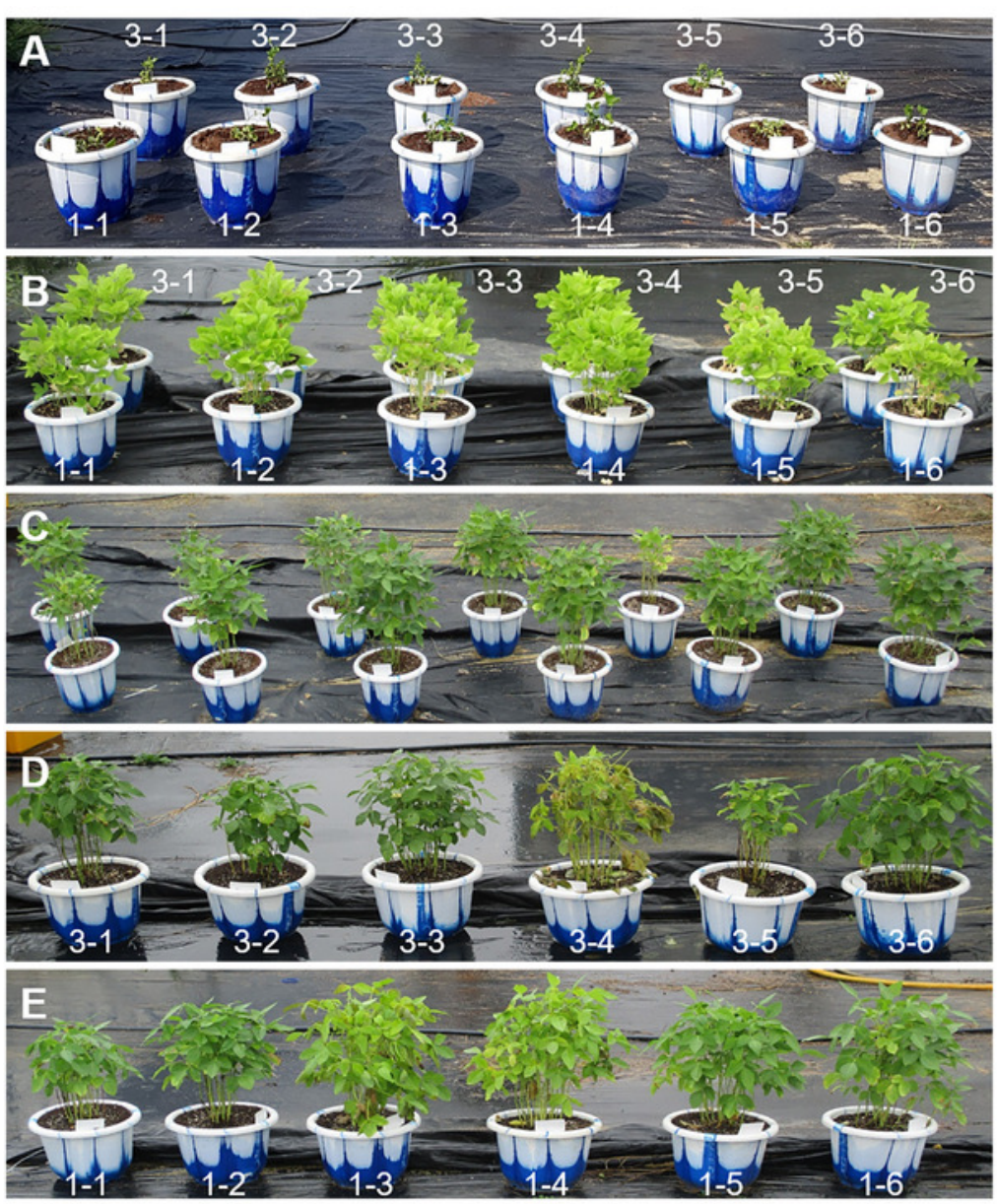
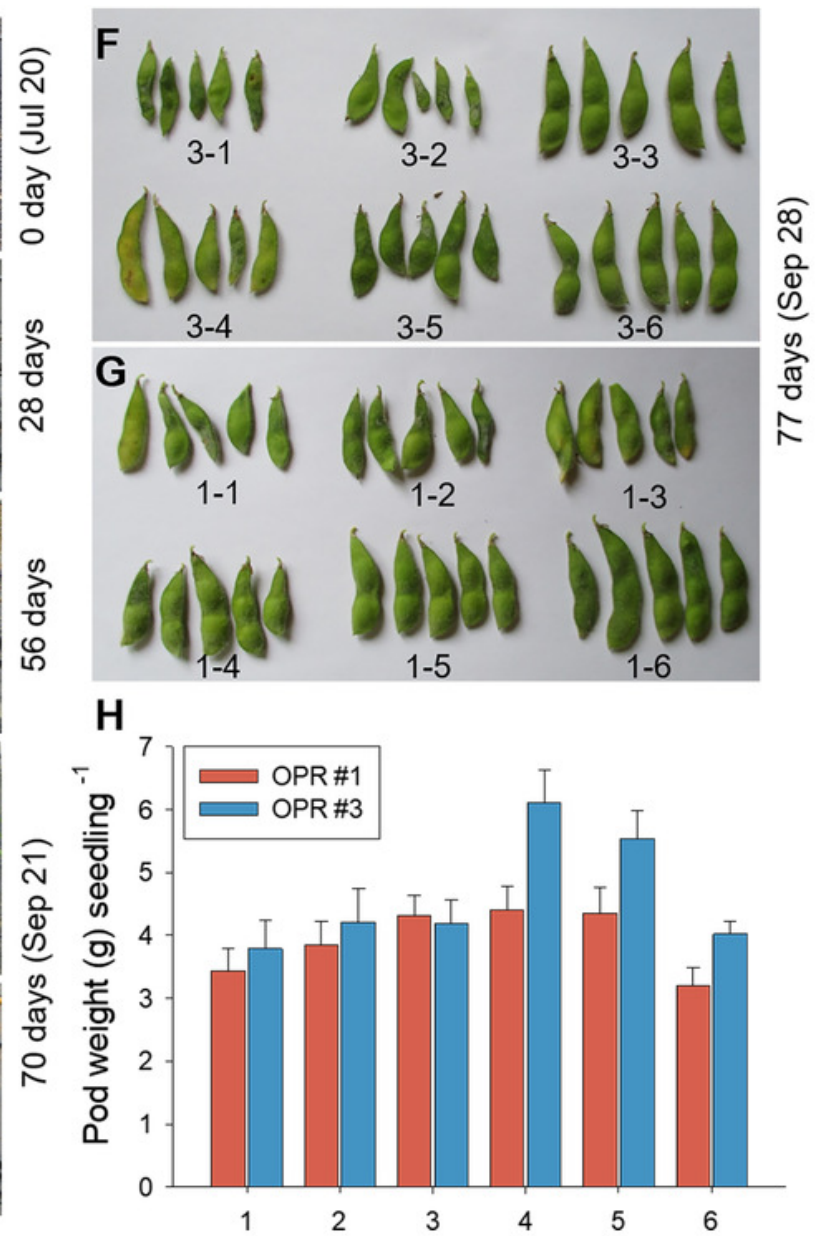


\section{Table $\mathbf{1}$ (on next page)}

Proximate and ultimate analyses of the harvested biomass during mass cultivation

Table 1: Proximate and ultimate analyses of the harvested biomass during mass cultivation 


\begin{tabular}{|c|c|c|c|c|c|c|c|c|c|c|c|c|c|c|c|c|}
\hline & \multicolumn{2}{|c|}{ APR } & \multicolumn{2}{|c|}{ MAY } & \multicolumn{2}{|c|}{ JUN } & \multicolumn{2}{|c|}{ JUL } & \multicolumn{2}{|c|}{ AUG } & \multicolumn{2}{|c|}{ SEP } & \multicolumn{2}{|c|}{ OCT } & \multicolumn{2}{|c|}{ NOV } \\
\hline & $\mathrm{O} 1$ & $\mathrm{O} 3$ & O1 & $\mathrm{O} 3$ & O1 & $\mathrm{O} 3$ & $\mathrm{O} 1$ & $\mathrm{O} 3$ & $\mathrm{O} 1$ & $\mathrm{O} 3$ & O1 & $\mathrm{O} 3$ & $\mathrm{O} 1$ & $\mathrm{O} 3$ & $\mathrm{O} 1$ & $\mathrm{O} 3$ \\
\hline \multicolumn{17}{|l|}{ Proximate analysis (wt \%) } \\
\hline Moisture & $\begin{array}{c}7.4 \\
\pm 0.4\end{array}$ & $\begin{array}{c}6.3 \\
\pm 0.0\end{array}$ & $\begin{array}{c}8.3 \\
\pm 0.2\end{array}$ & $\begin{array}{c}6.9 \\
\pm 0.4\end{array}$ & $\begin{array}{c}6.3 \\
\pm 0.2\end{array}$ & $\begin{array}{c}7.0 \\
\pm 0.1\end{array}$ & $\begin{array}{c}5.9 \\
\pm 0.1\end{array}$ & $\begin{array}{c}4.2 \\
\pm 0.3\end{array}$ & $\begin{array}{c}5.0 \\
\pm 0.0\end{array}$ & $\begin{array}{c}6.9 \\
\pm 0.0\end{array}$ & $\begin{array}{c}5.2 \\
\pm 0.2\end{array}$ & $\begin{array}{c}6.8 \\
\pm 0.2\end{array}$ & $\begin{array}{c}8.3 \\
\pm 0.2\end{array}$ & $\begin{array}{c}6.2 \\
\pm 0.2\end{array}$ & $\begin{array}{c}7.1 \\
\pm 0.1\end{array}$ & $\begin{array}{c}4.5 \\
\pm 0.1\end{array}$ \\
\hline Volatile matter & $\begin{array}{l}75.6 \\
\pm 0.6\end{array}$ & $\begin{array}{l}73.6 \\
\pm 0.4\end{array}$ & $\begin{array}{l}76.1 \\
\pm 0.2\end{array}$ & $\begin{array}{l}71.5 \\
\pm 0.1\end{array}$ & $\begin{array}{l}80.3 \\
\pm 0.3\end{array}$ & $\begin{array}{l}76.8 \\
\pm 0.6\end{array}$ & $\begin{array}{l}77.8 \\
\pm 0.3\end{array}$ & $\begin{array}{l}78.5 \\
\pm 0.4\end{array}$ & $\begin{array}{l}84.0 \\
\pm 0.1\end{array}$ & $\begin{array}{l}80.3 \\
\pm 0.1\end{array}$ & $\begin{array}{l}83.2 \\
\pm 0.1\end{array}$ & $\begin{array}{l}81.2 \\
\pm 0.4\end{array}$ & $\begin{array}{l}81.2 \\
\pm 0.0\end{array}$ & $\begin{array}{l}80.8 \\
\pm 0.1\end{array}$ & $\begin{array}{l}79.7 \\
\pm 0.1\end{array}$ & $\begin{array}{l}76.7 \\
\pm 0.1\end{array}$ \\
\hline Ash & $\begin{array}{l}17.0 \\
\pm 0.2\end{array}$ & $\begin{array}{l}20.1 \\
\pm 0.4\end{array}$ & $\begin{array}{l}15.6 \\
\pm 0.4\end{array}$ & $\begin{array}{l}21.7 \\
\pm 0.5\end{array}$ & $\begin{array}{l}13.4 \\
\pm 0.6\end{array}$ & $\begin{array}{l}16.3 \\
\pm 0.5\end{array}$ & $\begin{array}{l}16.2 \\
\pm 0.2\end{array}$ & $\begin{array}{l}17.3 \\
\pm 0.2\end{array}$ & $\begin{array}{l}11.0 \\
\pm 0.1\end{array}$ & $\begin{array}{l}12.8 \\
\pm 0.1\end{array}$ & $\begin{array}{l}11.7 \\
\pm 0.3\end{array}$ & $\begin{array}{l}12.0 \\
\pm 0.2\end{array}$ & $\begin{array}{c}10.5 \\
\pm 0.2\end{array}$ & $\begin{array}{l}12.9 \\
\pm 0.1\end{array}$ & $\begin{array}{l}13.2 \\
\pm 0.3\end{array}$ & $\begin{array}{l}18.8 \\
\pm 0.1\end{array}$ \\
\hline \multicolumn{17}{|l|}{ Ultimate analysis (wt \%) } \\
\hline Carbon (C) & $\begin{array}{l}39.9 \\
\pm 0.4\end{array}$ & $\begin{array}{l}38.6 \\
\pm 0.4\end{array}$ & $\begin{array}{l}41.7 \\
\pm 0.0\end{array}$ & $\begin{array}{l}39.1 \\
\pm 0.7\end{array}$ & $\begin{array}{l}43.6 \\
\pm 0.2\end{array}$ & $\begin{array}{l}40.8 \\
\pm 0.2\end{array}$ & $\begin{array}{l}42.5 \\
\pm 0.1\end{array}$ & $\begin{array}{l}41.8 \\
\pm 0.8\end{array}$ & $\begin{array}{l}45.8 \\
\pm 0.6\end{array}$ & $\begin{array}{l}45.7 \\
\pm 0.2\end{array}$ & $\begin{array}{l}42.7 \\
\pm 0.2\end{array}$ & $\begin{array}{l}43.0 \\
\pm 0.2\end{array}$ & $\begin{array}{l}46.1 \\
\pm 0.0\end{array}$ & $\begin{array}{l}45.1 \\
\pm 0.2\end{array}$ & $\begin{array}{l}43.5 \\
\pm 0.2\end{array}$ & $\begin{array}{l}37.9 \\
\pm 0.5\end{array}$ \\
\hline Hydrogen $(\mathrm{H})$ & $\begin{array}{c}5.4 \\
\pm 0.1\end{array}$ & $\begin{array}{c}5.4 \\
\pm 0.1\end{array}$ & $\begin{array}{c}6.0 \\
\pm 0.0\end{array}$ & $\begin{array}{c}5.3 \\
\pm 0.1\end{array}$ & $\begin{array}{c}6.3 \\
\pm 0.1\end{array}$ & $\begin{array}{c}5.7 \\
\pm 0.0\end{array}$ & $\begin{array}{c}6.2 \\
\pm 0.0\end{array}$ & $\begin{array}{c}5.9 \\
\pm 0.1\end{array}$ & $\begin{array}{c}6.6 \\
\pm 0.1\end{array}$ & $\begin{array}{c}6.4 \\
\pm 0.0\end{array}$ & $\begin{array}{c}6.5 \\
\pm 0.0\end{array}$ & $\begin{array}{c}6.5 \\
\pm 0.1\end{array}$ & $\begin{array}{c}6.5 \\
\pm 0.1\end{array}$ & $\begin{array}{c}6.4 \\
\pm 0.1\end{array}$ & $\begin{array}{c}6.4 \\
\pm 0.1\end{array}$ & $\begin{array}{c}5.3 \\
\pm 0.1\end{array}$ \\
\hline Nitrogen $(\mathrm{N})$ & $\begin{array}{c}5.4 \\
\pm 0.1\end{array}$ & $\begin{array}{c}5.8 \\
\pm 0.2\end{array}$ & $\begin{array}{c}6.2 \\
\pm 0.1\end{array}$ & $\begin{array}{c}5.5 \\
\pm 0.2\end{array}$ & $\begin{array}{c}7.0 \\
\pm 0.0\end{array}$ & $\begin{array}{c}5.4 \\
\pm 0.2\end{array}$ & $\begin{array}{c}5.7 \\
\pm 0.1\end{array}$ & $\begin{array}{c}5.8 \\
\pm 0.1\end{array}$ & $\begin{array}{c}5.3 \\
\pm 0.1\end{array}$ & $\begin{array}{c}6.9 \\
\pm 0.0\end{array}$ & $\begin{array}{c}6.0 \\
\pm 0.0\end{array}$ & $\begin{array}{c}6.0 \\
\pm 0.0\end{array}$ & $\begin{array}{c}7.2 \\
\pm 0.1\end{array}$ & $\begin{array}{c}5.6 \\
\pm 0.1\end{array}$ & $\begin{array}{c}7.1 \\
\pm 0.0\end{array}$ & $\begin{array}{c}4.0 \\
\pm 0.1\end{array}$ \\
\hline Sulfur (S) & $\begin{array}{c}0.4 \\
\pm 0.0\end{array}$ & $\begin{array}{c}0.5 \\
\pm 0.0\end{array}$ & $\begin{array}{c}0.4 \\
\pm 0.0\end{array}$ & $\begin{array}{c}0.4 \\
\pm 0.0\end{array}$ & $\begin{array}{c}0.5 \\
\pm 0.0\end{array}$ & $\begin{array}{c}0.4 \\
\pm 0.0\end{array}$ & $\begin{array}{c}0.4 \\
\pm 0.0\end{array}$ & $\begin{array}{c}0.4 \\
\pm 0.0\end{array}$ & $\begin{array}{c}0.5 \\
\pm 0.0\end{array}$ & $\begin{array}{c}0.5 \\
\pm 0.0\end{array}$ & $\begin{array}{c}0.4 \\
\pm 0.0\end{array}$ & $\begin{array}{c}0.4 \\
\pm 0.0\end{array}$ & $\begin{array}{c}0.6 \\
\pm 0.0\end{array}$ & $\begin{array}{c}0.4 \\
\pm 0.0\end{array}$ & $\begin{array}{c}0.5 \\
\pm 0.0\end{array}$ & $\begin{array}{c}0.3 \\
\pm 0.0\end{array}$ \\
\hline Oxygen (O) (by difference) & $\begin{array}{l}31.8 \\
\pm 0.4\end{array}$ & $\begin{array}{l}29.5 \\
\pm 0.2\end{array}$ & $\begin{array}{l}30.2 \\
\pm 0.3\end{array}$ & $\begin{array}{l}28.0 \\
\pm 1.5\end{array}$ & $\begin{array}{l}29.3 \\
\pm 0.4\end{array}$ & $\begin{array}{l}31.6 \\
\pm 0.1\end{array}$ & $\begin{array}{l}28.9 \\
\pm 0.2\end{array}$ & $\begin{array}{l}28.8 \\
\pm 1.1\end{array}$ & $\begin{array}{l}30.9 \\
\pm 0.9\end{array}$ & $\begin{array}{l}27.7 \\
\pm 0.0\end{array}$ & $\begin{array}{l}32.8 \\
\pm 0.2\end{array}$ & $\begin{array}{l}32.2 \\
\pm 0.2\end{array}$ & $\begin{array}{l}29.2 \\
\pm 0.3\end{array}$ & $\begin{array}{l}20.5 \\
\pm 0.2\end{array}$ & $\begin{array}{l}29.4 \\
\pm 0.0\end{array}$ & $\begin{array}{l}15.9 \\
\pm 0.4\end{array}$ \\
\hline HHV (MJ/kg) & $\begin{array}{l}17.0 \\
\pm 0.3\end{array}$ & $\begin{array}{l}17.0 \\
\pm 0.2\end{array}$ & $\begin{array}{c}18.6 \\
\pm 0.1\end{array}$ & $\begin{array}{l}17.2 \\
\pm 0.6\end{array}$ & $\begin{array}{l}19.8 \\
\pm 0.1\end{array}$ & $\begin{array}{l}17.7 \\
\pm 0.1\end{array}$ & $\begin{array}{c}19.5 \\
\pm 0.0\end{array}$ & $\begin{array}{l}18.8 \\
\pm 0.6\end{array}$ & $\begin{array}{l}20.8 \\
\pm 0.5\end{array}$ & $\begin{array}{l}20.9 \\
\pm 0.1\end{array}$ & $\begin{array}{l}19.4 \\
\pm 0.0\end{array}$ & $\begin{array}{c}19.5 \\
\pm 0.3\end{array}$ & $\begin{array}{l}21.0 \\
\pm 0.1\end{array}$ & $\begin{array}{l}20.5 \\
\pm 0.2\end{array}$ & $\begin{array}{l}20.0 \\
\pm 0.2\end{array}$ & $\begin{array}{l}15.9 \\
\pm 0.4\end{array}$ \\
\hline
\end{tabular}

2 Proximate and ultimate analyses of the harvested biomass during mass cultivation

$3 * \mathrm{O} 1$ : Open pond raceway \#1, O3: Open pond raceway \#3 


\section{Table 2 (on next page)}

Biodiesel quality analysis of the harvested biomass during mass cultivation

Table 2: Biodiesel quality analysis of the harvested biomass during mass cultivation 
Table 2:

\begin{tabular}{|c|c|c|c|c|c|c|c|c|c|c|c|c|c|c|c|c|c|c|}
\hline & \multicolumn{2}{|c|}{ APR } & \multicolumn{2}{|c|}{ MAY } & \multicolumn{2}{|c|}{ JUN } & \multicolumn{2}{|c|}{ JUL } & \multicolumn{2}{|c|}{ AUG } & \multicolumn{2}{|c|}{ SEP } & \multicolumn{2}{|c|}{ OCT } & \multicolumn{2}{|c|}{$\mathrm{NOV}$} & \multirow{2}{*}{$\begin{array}{c}\text { EN } \\
14214\end{array}$} & \multirow{2}{*}{$\begin{array}{l}\text { ASTM } \\
\text { D6751 }\end{array}$} \\
\hline & $\mathrm{O} 1$ & $\mathrm{O} 3$ & O1 & $\mathrm{O} 3$ & $\mathrm{O} 1$ & $\mathrm{O} 3$ & $\mathrm{O} 1$ & $\mathrm{O} 3$ & O1 & $\mathrm{O} 3$ & O1 & $\mathrm{O} 3$ & $\mathrm{O} 1$ & $\mathrm{O} 3$ & $\mathrm{O} 1$ & $\mathrm{O} 3$ & & \\
\hline SV & 205.5 & 202.7 & 203.5 & 205.6 & 205.7 & 202.5 & 202.5 & 201.5 & 200.9 & 203.0 & 202.4 & 202.3 & 204.2 & 199.0 & 204.1 & 198.1 & - & - \\
\hline $\begin{array}{c}\mathrm{IV}\left(\mathrm{g} \mathrm{I}_{2}\right. \\
\left.100 \mathrm{~g}^{-1} \text { fat }\right)\end{array}$ & 63.3 & 121.2 & 90.2 & 58.3 & 67.4 & 58.3 & 68.1 & 84.17 & 92.4 & 106.3 & 108.7 & 111.1 & 94.6 & 125.8 & 102.0 & 112.2 & $\leq 120$ & - \\
\hline $\mathrm{CN}$ & 60.8 & 49.2 & 55.2 & 49.2 & 59.6 & 62.6 & 60.2 & 57.5 & 56.0 & 52.1 & 51.8 & 51.4 & 54.1 & 49.2 & 52.5 & 52.6 & $\geq 51$ & $\geq 47$ \\
\hline DU (wt \%) & 52 & 66 & 67 & 52 & 55 & 53 & 55 & 62 & 69 & 69 & 71 & 74 & 69 & 87 & 64 & 82 & - & - \\
\hline $\begin{array}{c}\mathrm{LCSF}(\mathrm{wt} \\
\%)\end{array}$ & 4.1 & 4.6 & 3.6 & 5.1 & 3.8 & 4.6 & 4.2 & 4.8 & 4.8 & 4.1 & 4.3 & 4.3 & 3.9 & 3.4 & 3.6 & 3.6 & - & - \\
\hline $\mathrm{CFPP}\left({ }^{\circ} \mathrm{C}\right)$ & -3.7 & -2.2 & -5.2 & -0.5 & -4.4 & -2.0 & -3.4 & -1.3 & -1.3 & -3.7 & -2.9 & -3.1 & -4.3 & -5.9 & -5.2 & -5.3 & $\leq 5 / \leq-20$ & - \\
\hline $\begin{array}{l}\text { Oxidation } \\
\text { stability (h) }\end{array}$ & 24.5 & 10.0 & 10.7 & 18.9 & 17.4 & 17.3 & 12.2 & 11.9 & 10.5 & 9.2 & 9.1 & 8.8 & 9.5 & 7.8 & 10.3 & 9.4 & $\geq 6$ & $\geq 3$ \\
\hline $\begin{array}{l}\text { Kinematic } \\
\text { viscosity } \\
\text { (v) }\left(\mathrm{mm}^{2}\right. \\
\left.\mathrm{s}^{-1}\right)\end{array}$ & 4.0 & 3.8 & 3.9 & 3.8 & 4.0 & 4.2 & 4.1 & 4.1 & 4.0 & 3.9 & 3.9 & 3.9 & 3.9 & 3.9 & 3.8 & 4.0 & $3.5-5.0$ & $1.9-6.0$ \\
\hline $\begin{array}{l}\text { Density }(\rho) \\
\left(\mathrm{g} \mathrm{cm}^{-3}\right)\end{array}$ & 0.87 & 0.88 & 0.88 & 0.88 & 0.87 & 0.87 & 0.87 & 0.88 & 0.88 & 0.88 & 0.88 & 0.88 & 0.88 & 0.88 & 0.88 & 0.88 & $\begin{array}{c}0.86- \\
0.90\end{array}$ & $\begin{array}{c}0.82- \\
0.90\end{array}$ \\
\hline
\end{tabular}

2 Biodiesel quality analysis of the harvested biomass during mass cultivation

$3 * \mathrm{O} 1$ : Open pond raceway \#1, O3: Open pond raceway \#3 